\title{
1 Dissecting genetic and sex-specific host heterogeneity in pathogen transmission
}

2 potential

3

4

5 Jonathon A. Siva-Jothy'; Pedro F. Vale $e^{1,2}$

6

71 Institute of Evolutionary Biology, School of Biological Sciences, University of

8 Edinburgh, EH9 3FL Edinburgh, United Kingdom

$9{ }^{2}$ Centre for Immunity, Infection and Evolution, University of Edinburgh, EH9 3FL

10 Edinburgh, United Kingdom 


\section{Abstract}

12 Heterogeneity in disease transmission is widespread and, when not accounted for, can

13 produce unpredictable outbreaks of infectious disease. Despite this, precisely how

14 different sources of variation in host traits drive heterogeneity in disease transmission is

15 poorly understood. Here we dissected the sources of variation in pathogen transmission

16 using Drosophila melanogaster and Drosophila C Virus as a host-pathogen model

17 system. We found that infected lifespan, viral growth, virus shedding, and viral load at

18 death were all significantly influenced by fly genetic background, sex and female mating

19 status. To understand how variation in each of these traits may generate heterogeneity

20 in disease transmission, we estimated individual transmission potential by integrating

21 data on virus shedding and lifespan alongside previously collected data on social

22 aggregation. We found that $\sim 15 \%$ of between-individual heterogeneity in disease

23 transmission was explained by a significant interaction between genetic and sex-specific

24 variation. We also characterised the amount of variation in viral load, virus shedding, and

25 lifespan following infection that could be explained by genetic background and sex.

26 Amongst the determinants of individual variation in disease transmission these sources

27 of host variation play roles of varying importance, with genetic background generally

28 playing the largest role. Our results highlight the importance of characterising sources of

29 variation in multiple host traits when studying disease transmission at the individual-level.

31 Keywords: Superspreaders; viral transmission; Drosophila C Virus; Drosophila

32 melanogaster, individual variation; heterogeneity; $V$; $R_{0}$; genetic variation; sexual

33 dimorphism 
Introduction

35 Individual host heterogeneity in disease spread is commonly observed across a wide range of infectious diseases (Woolhouse et al., 1997; Lloyd-Smith et al., 2005; Paull et al., 2011). Such heterogeneity is so common that it has been generalised into the '20-80 rule' because of the frequent observation that $20 \%$ of hosts contribute to roughly $80 \%$ of transmission (Shaw \& Dobson, 1995; Wilson et al., 2002; Woolhouse et al., 1997). More extreme forms of heterogeneity can result in very rare 'superspreading' individuals capable of causing large outbreaks of infectious disease in human and animal populations (Brooks-Pollock, Roberts, \& Keeling, 2014; Lloyd-Smith et al., 2005). A superspreader of particular infamy is Mary Mallon who became known as 'Typhoid Mary' by infecting over 50 people with Salmonella typhi while working as a cook in New York during the early $20^{\text {th }}$ century (Marineli, Tsoucalas, Karamanou, \& Androutsos, 2013). More recently, the 2003 outbreaks of SARS in Singapore and Hong Kong were greatly accelerated by a few superspreading individuals who caused over $70 \%$ of all SARS transmission (Li et al., 2004).

Outbreaks of infectious disease are often difficult to predict, especially when the effect of superspreaders are not accounted for by traditional assessments of outbreak risk. A widely used metric for the rate of pathogen spread is the basic reproductive number, $R_{0}$, which estimates the average number of expected secondary infections caused by a single infected individual in a completely susceptible population. By focussing on the population average, $R_{0}$ conceals outliers with a potentially higher propensity to spread disease (Lloyd-Smith et al., 2005; Paull et al., 2012; VanderWaal \& Ezenwa, 2016). A clearer understanding of what drives heterogeneity in disease transmission requires a framework capable of accounting

59 for such between-individual variation, which could enable more efficient control

60 strategies that specifically target and treat high-risk individuals (Lloyd-Smith et al., 61 2005). The importance of predicting high-risk individuals before outbreaks occur has pushed understanding the causes of heterogeneity in disease transmission to the 
63 forefront of epidemiology and disease ecology research (Gervasi, Civitello, Kilvitis, \&

64 Martin, 2015; Paull et al., 2012; Stein, 2011; VanderWaal \& Ezenwa, 2016).

65

66 Despite being commonplace, the underlying causes of heterogeneity in pathogen 67 transmission remain elusive. Individual variation in host contact networks may be an 68 important factor: it was Typhoid Mary's position as a cook which exposed her to so 69 many susceptible individuals. However, what enabled Typhoid Mary to stay in this role was her status as an asymptomatic carrier of the infection, which led to her release from quarantine on several occasions (Marineli et al., 2013). Similarly, the absence of symptoms in a number of SARS superspreaders delayed their admission to hospital and allowed them to continue spreading the virus (Centers for Disease Control and Prevention (CDC), 2003). These examples help underline that achieving a detailed understanding of the sources of heterogeneity in pathogen transmission is challenging because it results from complex interactions between multiple host behavioural, physiological, and immune traits. By dissecting the underlying genetic and sex-specific sources of variation in these traits we can assess how they influence three key components of pathogen transmission: contact rate between infected and susceptible individuals, the likelihood that contact will result in infection, and the duration of infection (VanderWaal \& Ezenwa, 2016).

83 Infected-susceptible host contact rate is predominantly determined by host 84 behaviours affecting locomotion and aggregation. Contact rates are also affected by 85 population density (Keeling \& Rohani, 2007), social group size (Patterson \& 86 Ruckstuhl, 2013), and behavioural syndromes (Keiser, Pinter-Wollman, et al., 2016). 87 Social networks often exhibit extreme heterogeneity in the wild (Godfrey, 2013; 88 Rushmore et al., 2013) and factors such as host genotype, sex condition, age and 89 personality have been demonstrated to affect social aggregation in lab systems (de 90 Bono \& Bargmann, 1998; Keiser, Howell, et al., 2016; Saltz, 2011; Siva-Jothy \& Vale, 91 2019). Once individuals acquire an infection, their ability to clear and shed pathogens 
92 is chiefly determined by physiological and immune mechanisms. Variation in these

93 mechanisms chiefly influence the likelihood of pathogen transmission and the

94 duration of infection (Grassly \& Fraser, 2008; VanderWaal \& Ezenwa, 2016). Many

95 genetic and environmental sources of variation in physiological immunity have been

96 described (Bou Sleiman et al., 2015; Lazzaro Brian P \& Little Tom J, 2009; Ponton et

97 al., 2013) including coinfection (Budischak et al., 2015; Lass Sandra et al., 2013),

98 nutrition (Cornet, Bichet, Larcombe, Faivre, \& Sorci, 2014; Vale, Choisy, \& Little,

99 2013), and stress (Beldomenico \& Begon, 2010; Capitanio et al., 2008). It is relevant

100 to note that most studies have addressed the effects of behavioural, physiological

101 and immune traits on transmission in isolation of one another. However, there is

102 increasing evidence that transmission heterogeneity is often explained by coupled

103 heterogeneities in these traits and how they may covary (Bolzoni, Real, \& Leo, 2007;

104 Farrington, Whitaker, Unkel, \& Pebody, 2013; White, Forester, \& Craft, 2018). To fully

105 understand the sources of heterogeneity in pathogen transmission, it is therefore

106 essential to measure multiple behavioural, physiological, and immune traits in hosts.

108 In the present work we aimed to test how common sources of variation between

109 individuals (genetic background, sex and mating status) contribute to individual

110 heterogeneity in pathogen transmission potential. The fruit fly, Drosophila

111 melanogaster, is a powerful and genetically tractable model of infection, immunity

112 and behaviour (Apidianakis \& Rahme, 2009; Sokolowski, 2001). This makes it an ideal

113 model system to investigate heterogeneity in pathogen transmission in the highly

114 controlled conditions of a laboratory. We infected males and females from a range of

115 naturally derived genotypes with Drosophila C Virus (DCV), a horizontally transmitted

116 fly pathogen that causes behavioural, physiological and metabolic pathologies

117 (Arnold, Johnson, \& White, 2013; Chtarbanova et al., 2014; Gupta, Stewart, Rund,

118 Monteith, \& Vale, 2017; Vale \& Jardine, 2015). We then quantified host traits and

119 infection outcomes that directly impact pathogen transmission: (1) the infected

120 lifespan, (2) the internal viral load, (3) how much virus was shed, and (4) the viral load 
121 at death (VLAD). Finally, we integrated these measurements alongside previously

122 described data on variation in social aggregation (Siva-Jothy \& Vale, 2019) into a

123 composite metric of individual transmission potential, $V$ (Lloyd-Smith et al., 2005;

124 VanderWaal \& Ezenwa, 2016). Estimations of individual transmission potential, $V$,

125 allowed us to assess how genetic and sex-specific variation affects between-

126 individual heterogeneity in pathogen transmission. 


\section{Materials \& Methods}

\section{Flies \& Rearing Conditions}

129 Flies used in experiments were 3-5 days old and came from ten lines of the Drosophila

130 Genetic Resource Panel (DGRP). These genetic backgrounds are five of the most 131 resistant and susceptible to systemic Drosophila C Virus infection (Magwire et al., 132 2012). Virgin females were isolated from males within 7 hours of eclosion. Mated 133 females and males were produced by rearing one female with one male for 24 hours.

134 Mating was confirmed using oviposition within the following 24 hours and these egg's 135 subsequent development. Flies were reared in plastic vials on a standard diet of 136 Lewis medium at $18 \pm 1^{\circ} \mathrm{C}$ with a 12 hour light:dark cycle. Stocks were tipped into new 137 vials approximately every 14 days. One month before the experiments, flies were 138 maintained at low density ( 10 flies per vial) for two generations at $25 \pm 1^{\circ} \mathrm{C}$ with a 12 139 hour light:dark cycle.

\section{Virus Culture \& Infection}

142 The Drosophila C Virus (DCV) isolate used in this experiment was originally isolated 143 in Charolles, France and grown in Schneider Drosophila Line 2 (DL2) as previously 144 described (Vale and Jardine, 2015b), diluted ten-fold (108 infectious units per $\mathrm{ml}$ ) in 145 TRIS-HCl solution $(\mathrm{pH}=7.3)$, aliquoted and frozen at $-70^{\circ} \mathrm{C}$ until required. To infect 146 with DCV, flies were pricked in the pleural suture with a $0.15 \mathrm{~mm}$ diameter pin, bent 147 at $90^{\circ} \sim 0.5 \mathrm{~mm}$ from the tip, dipped in DCV.

\section{Measuring Lifespan and Viral Load at Death}

150 Lifespan and viral load at death were measured in the same fly. Following DCV 151 infection, flies were isolated and reared in standard vials. Flies were then monitored 152 every day until all individuals died, whereupon they were removed from vials, fixed in $15350 \mu \mathrm{l}$ of TRI-reagent and frozen at $-70^{\circ} \mathrm{C}$, to await DCV titre at death quantification. For 154 twenty-seven of thirty treatment groups, the lifespan following infection and viral load 
155 at death was measured for $n=17-20$, three treatment groups consisted of $n=7-15$ flies

156 (Table S1).

157

\section{Viral Growth and Shedding Measurement Setup}

159 Due to destructive sampling, we measured the viral load and shedding of single flies 160 at a single time point, either 1-, 2- or 3-days post-infection (DPI). Following DCV 161 infection, single flies were placed into $1.5 \mathrm{ml}$ Eppendorf tubes with $\sim 50 \mu$ l of Lewis 162 medium in the bottom of the tube. To measure viral shedding, flies were transferred 163 to tubes for 24 hours, immediately following 1 or 2 days after systemic infection. After 164 living in these tubes for a further 24 hours, flies were removed and homogenised in $16550 \mu \mathrm{l}$ of TRI-reagent, tubes were also washed out with $50 \mu \mathrm{l}$ of TRI-reagent by 166 vortexing. These samples were then frozen at $-70^{\circ} \mathrm{C}$, to await DCV quantification by 167 qPCR. For each combination of sex and genetic background over the three days vial load and virus shedding was measured, $\mathrm{n}=7-15$ flies were measured (Table S2-S4).

\section{DCV RNA Extraction}

171 RNA was extracted from viral load at death and viral shedding samples by Phenol-

172 Chloroform extraction. Samples were thawed on ice for 30 minutes before being 173 incubated at room temperature for 5 minutes to allow dissociation of nucleo-protein 174 complex. Samples were then centrifuged at $12,000 \times g$ for 10 minutes at $4^{\circ} \mathrm{C}$ after 175 which large debris was removed. For phase separation, samples were shaken vigorously for 15 seconds, $10 \mu \mathrm{l}$ of chloroform added, incubated at room temperature

177 for a further 3 minutes before being centrifuged at $12,000 \times g$ for 15 minutes at $4^{\circ} \mathrm{C}$.

178 Following phase separation, the upper aqueous layer was removed from each sample and added to $25 \mu \mathrm{l}$ of isopropanol, tubes were then inverted twice, before

180 being centrifuged at $12,000 \times g$ for 10 minutes at $4^{\circ} \mathrm{C}$. Precipitated RNA was then 181 washed by removing the supernatant, and re-dissolving the RNA pellet in $50 \mu$ of $75 \%$ 182 ethanol before being centrifuged at $7,500 \times \mathrm{g}$ for 5 minutes at $4^{\circ} \mathrm{C}$. RNA suspension 183 was achieved by removing $40 \mu$ l of the ethanol supernatant, allowing the rest to dry 
184 by evaporation and dissolving the remaining RNA pellet in $20 \mu$ l of RNase-free water.

185 We extracted RNA from flies after 1, 2 or 3 days of infection using a semi-automatic 186 MagMAX Express Particle Processor using the MagMAX-96 total RNA isolation kit

187 manufacturer's protocol (Life Technologies, 2011) with the elution step extended to

18818 minutes. RNA samples were stored at $-70^{\circ} \mathrm{C}$ to await reverse transcription.

190 Reverse transcription \& qPCR Protocol

191 Extracted RNA was reverse-transcribed with M-MLV reverse transcriptase and 192 random hexamer primers, before being diluted 1:1 with nuclease free water. cDNA 193 samples were stored at $-20^{\circ} \mathrm{C}$ to await qPCR analysis. DCV titre was quantified by 194 qPCR using Fast SYBR Green Master Mix in an Applied Biosystems StepOnePlus 195 system. Samples were exposed to a PCR cycle of $95^{\circ} \mathrm{C}$ for 2 minutes followed by 40 196 cycles of: $95^{\circ} \mathrm{C}$ for 10 seconds followed by $60^{\circ} \mathrm{C}$ for 30 seconds. Forward and reverse 197 primers used included 5'-AT rich flaps to improve fluorescence (DCV_Forward: 5' 198 AATAAATCATAAGCCACTGTGATTGATACAACAGAC 3'; DCV Reverse: 5' AATAAATCATAAGAAGCACGATACTTCTTCCAAACC 3'). Across all plates, two technical replicates were carried out per sample. DCV titre was calculated by absolute quantification, using a standard curve created from a 10-fold serial dilution $\left(1-10^{-12}\right)$ of DCV cDNA. Our detection threshold was calculated for each plate using the point at which two samples on our standard curve gave the same Ct value. The point of redundancy in a standard curve was taken to be equivalent to 0 viral particles. Due to our detection protocol measuring viral copies of RNA, we cannot comment on the viability of any detected virus. We transformed our measurements of viral RNA transformed in order for them to represent the amount of virus growing inside a whole fly rather than the amount in the qPCR well sample. To account for dilution between RNA extraction and qPCR we transformed DCV RNA samples by a

210 factor of 3125, to represent the amount of DCV growing in, or shed by, flies. The mean

211 qPCR efficiency was $116 \%$ with a standard error of $\pm 2.9 \%$ 


\section{Calculating Between-Individual Variation in Transmission Potential, $V$}

214 We used measures of virus shedding, lifespan following infection, and social 215 aggregation to predict individual transmission potential. We integrated these

216 measures based on a simple framework that describes transmission potential as a

217 function of contact rate between susceptible and infected individuals, the likelihood 218 that such contact will result in infection, and the duration of the infectious period

219 (VanderWaal \& Ezenwa, 2016). Using previously analysed data on social aggregation

220 (Siva-Jothy \& Vale, 2019), we used nearest neighbour distance as a measure of 221 contact rate. Flies that aggregated more closely to conspecifics, have a higher 222 contact rate, and are therefore more likely to spread DCV. We also assume that 223 transmission likelihood increases with virus shedding. We therefore take the amount 224 of virus shed by flies as a proximate measure of the likelihood that contact will result 225 in infection. Using these traits, individual transmission potential, $V$, was calculated as:

$$
V=\frac{\text { (Virus Shedding Titre }) \times(\text { Lifespan })}{\text { (Aggregation Distance })}
$$

229 Aggregation distance, lifespan following infection and virus shedding were all 230 measured in separate experiments. Therefore, to calculate $V$ as a measure of 231 individual transmission potential, we simulated theoretical individuals by 232 bootstrapping trait values sampled from each of these three datasets. We simulated

23360 individuals for each combination of sex and genetic background, assuming no 234 specific covariance structure between traits, that is, all possible trait combinations were considered.

237 Statistical Analysis

238 Across all experiments, generalised linear models (GLMs) were used to analyse 239 continuous response variables and logistic regressions were used to analyse 
240 proportions. An effect of sex or mating was analysed in separate models comparing

241 males or virgin females to the same dataset of mated females, respectively.

242

243 To analyse lifespan, two GLMs were constructed containing a three-way interaction 244 genetic background, VLAD, and sex or mating (Table S6). The two GLMs for VLAD, 245 contained either a two-way interaction between genetic background and sex or a 246 two-way interaction between genetic background and mating (Table S6).

248 Due to zero-inflation, we used two models to sequentially analyse both viral load and 249 virus shedding data. Viral load and virus shedding are broken down into qualitative 250 (the proportion of non-zero values) and quantitative variation (differences between non-zero values). First, we conducted logistic regressions on all of the values in these datasets and analysed the proportion of values that were greater than zero. Logistic regressions analysing sex-differences in viral load included DPI (a 3-level factor: 1, 2 or 3 days) and an interaction between genetic background and sex (Table S6). For analysing the effect of mating in females on viral load, logistic regressions included DPI and an interaction between genetic background and mating (Table S6). Logistic regressions of virus shedding used a similar model that also included quantitative viral load as a predictor (Table S6). After these logistic regressions, zeroes were removed from all datasets to analyse the subset of positive-values. The GLMs used to analyse these subsets included the same predictors as their corresponding logistic regressions, for viral load: an interaction between genetic background and sex or mating, alongside DPI, with the inclusion of quantitative viral load for virus shedding

\section{3 (Table S6).}

265 Due to zero-inflation $V$ was also analysed with a logistic regression followed by a

266 GLM. A logistic regression was used to analyse the proportion of $V$ values that were 267 greater than zero with a two-way interaction between sex and genetic background 268 as predictors (Table S6). Zero-values of $V$ were then removed from the dataset, and 
269 a GLM was used to analyse differences in the size of $V$, with an interaction between

270 sex and genetic background included as a predictor (Table S6).

271

272 We calculated the amount of deviance and variance explained by predictors in 273 logistic regressions and GLMs, respectively, by dividing the total deviance or 274 variance explained by the model. Where appropriate, we corrected for multiple 275 testing using Bonferroni correction. All statistical analyses and graphics produced in 276 R 3.3.0 using the ggplot2(Wickham, 2016), Ime4 (Bates, Mächler, Bolker, \& Walker, 277 2015) and multcomp (Hothorn, Bretz, \& Westfall, 2008) packages. 


\section{Results}

\section{Lifespan Following Infection}

280 Infected lifespan varied significantly between males and females and the extent of

281 this variation differed between host genetic backgrounds (Figure 1a; Table 1).

282 Genetic background explained the most variance of any predictor across models 283 assessing mating (7\%) and sex (10.9\%). Interactions with sex and mating also

284 explained a further $2.7 \%$ and $1.5 \%$, respectively (Figure 5; Table 1). We found no

285 evidence that mating affected the lifespan of females following DCV infection (Figure

286 1a; Table 1). Viral load at death (VLAD) was not affected by genetic background, sex

287 or female mating status (Figure 1b; Table 2), and flies that died sooner following

288 infection had greater VLAD than those that died later (Figure 1c; Table 1). 
(a)

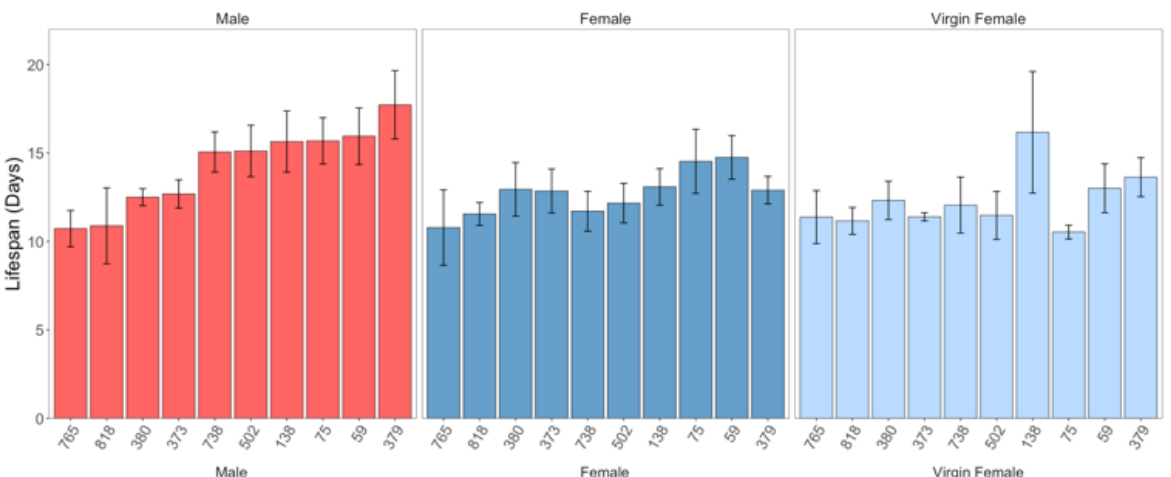

(b)

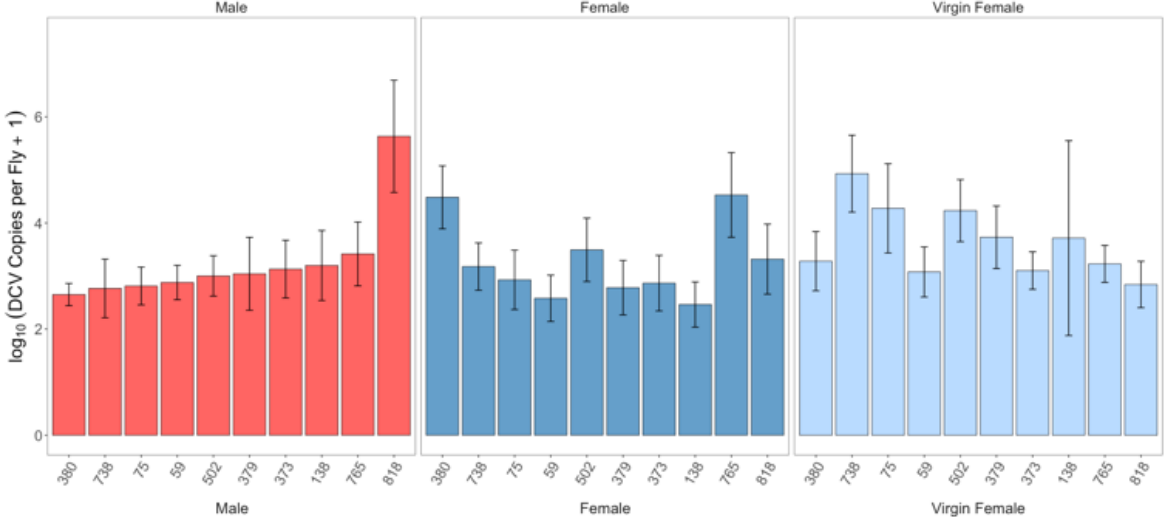

(c)

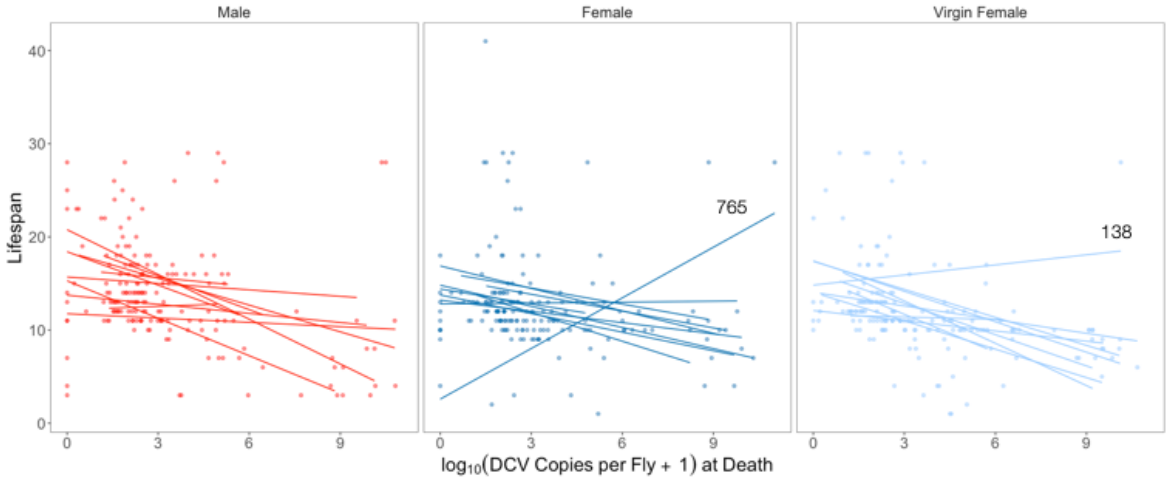

291 Figure 1. Mean \pm SE (a) lifespan in days following infection and (b) the viral load at death in males (red), mated females (blue), and virgin females (pale blue) of ten

293 genetic backgrounds. The x-axis shows the line number form the DGRP panel and is

294 in ascending order according to male flies. (c) the relationship between lifespan

295 following infection and the viral load of flies at death. Each point is an individual male

296 (red), mated female (blue), or virgin female (pale blue) fly. The nature of this

297 relationship within each genetic background is represented by a line of best fit with

298 outlier backgrounds labelled. 


\section{Viral Load}

303 A substantial number of flies did not have detectable loads of DCV. These zero-values

304 reflect qualitative variation and are likely caused by viral titres below the detection

305 threshold of our qPCR and therefore reflect individuals with very low DCV loads, or

306 no virus at all. We found extensive genetic variation in qualitative DCV load (Figure

307 2a; Table 3) which was affected by sex (Figure 2a; Table 3) and female mating status

308 (Figure 2a; Table 3). Relatively little deviance was explained by sex (0.002\%), mating

$309(0.13 \%)$, or genetic background in models testing sex (1.18\%) and mating (2.83\%)

310 effects. The predictors that explained the most deviance were the interactions

311 between genetic background and sex (5.58\%) or mating (4.92\%) (Figure 5; Table 3).

312 The size of non-zero DCV loads reflects quantitative variation and was affected by

313 similar interactions between mating and sex with genetic background (Figure 2b;

314 Table 4). While $<1 \%$ of variance was explained by sex and mating, much more was

315 explained by genetic background (7.94\% and $11 \%)$ alongside its interactions with

316 sex (19.2\%) and mating (4.38\%) (Figure 5; Table 4).

318 The number of detectable DCV loads decreased following 1-day post-infection

319 (pairwise comparison, $\mathrm{p}<0.0001$ ) and remained lower than day 1 at day 3 (pairwise

320 comparison, $p=0.0016)$. There were significant changes in quantitative DCV load

321 variation over the first three days of infection. Viral load peaked 2-days post-infection

322 (pairwise comparison, $\mathrm{p}=0.0012$ ), before decreasing to the same level as 1-day post-

323 infection at 3-days post-infection (pairwise comparison, $p=0.068$ ). 
(a)

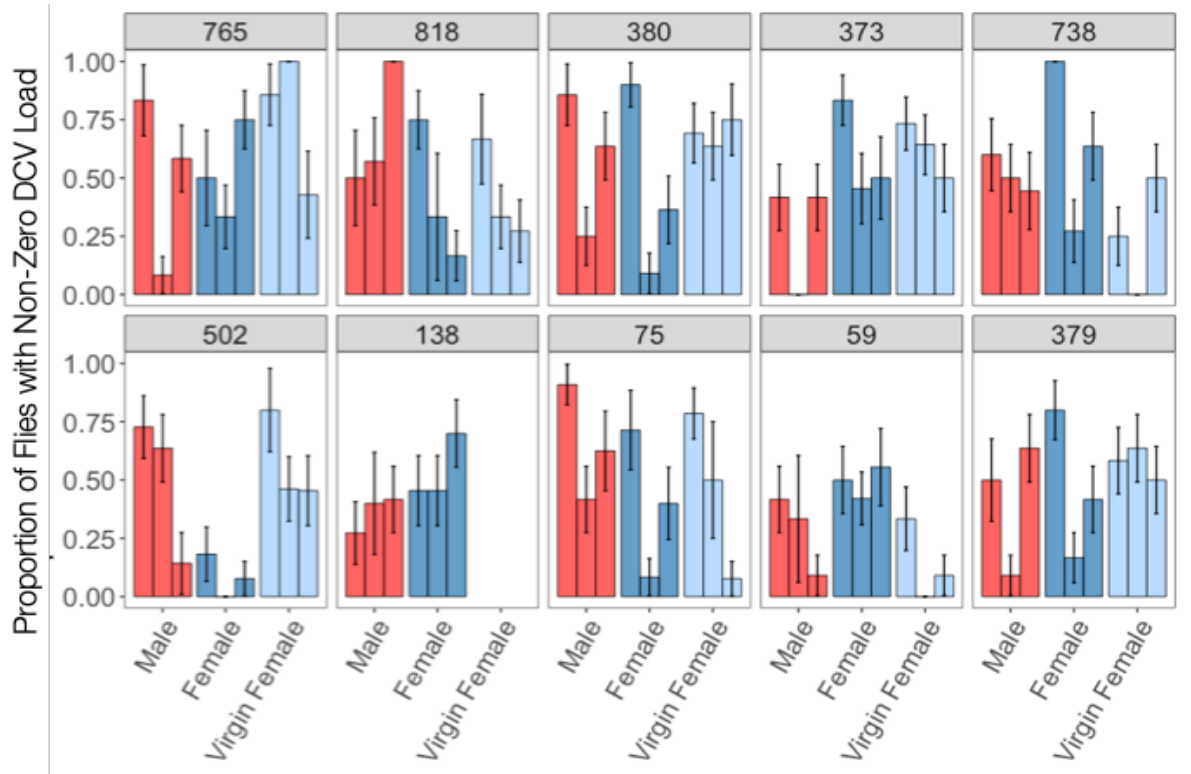

(b)

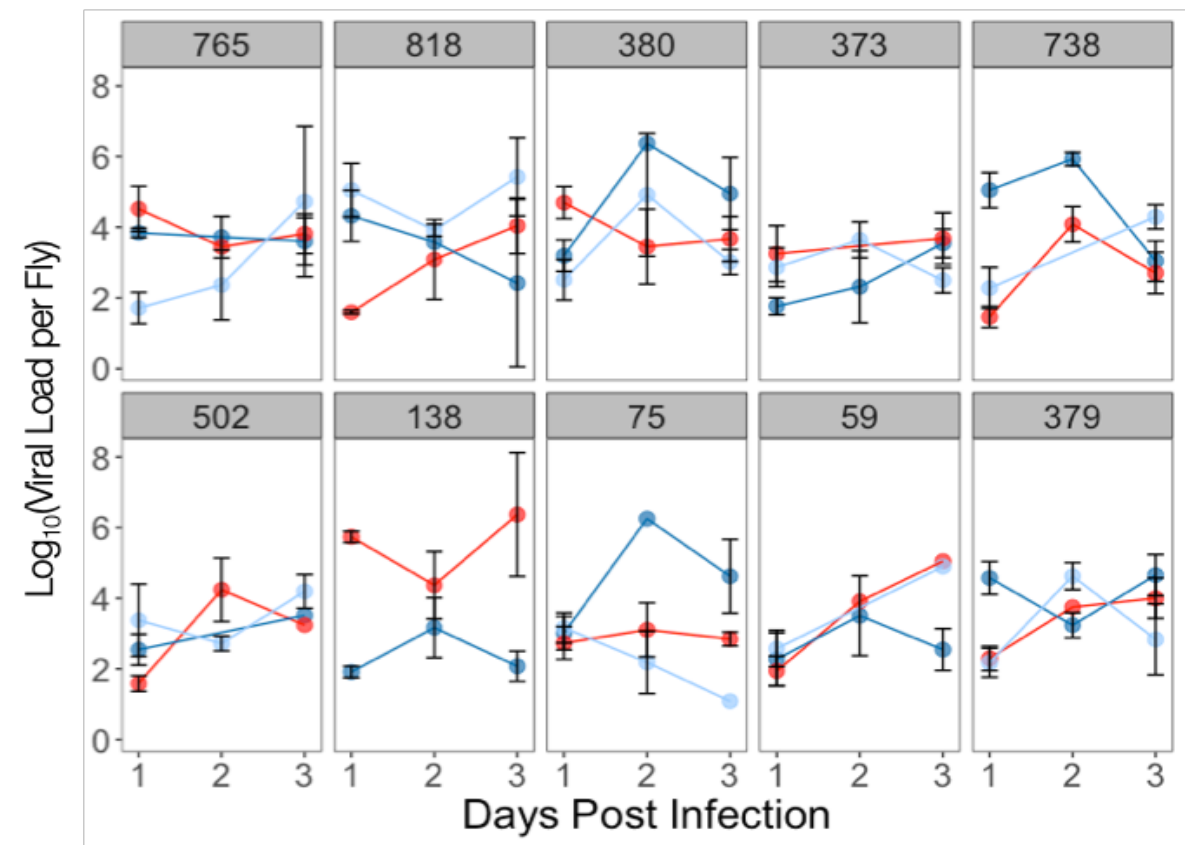

Figure 2. Mean $\pm S E$ (a) proportion of flies with non-zero loads of DCV and the (b) viral

327 titre of flies with non-zero DCV loads, over the first 3 days of infection. Across both

328 panels, numbers in each pane denote the genetic background from the DGRP, while

329 the colour of bars, points and lines represent sex and mating status. Males are shown

330 in red, mated females in blue, and virgin females in pale blue. Bars of the same colour

331 in each in pane in panel (a) represent (from left to right) days 1, 2 and 3 of infection. 


\section{Virus Shedding}

337 Similar to measures of viral load, we did not detect DCV in the shedding of a number

338 of flies. Here, we interpret zeroes to be reflective of individuals that shed very low

339 titres of DCV, or no virus at all. Qualitative variation in DCV shedding was significantly

340 affected by genetic background, with sex modulating the extent of this difference

341 (Figure 3a; Table 5). Sex however, explained $<1 \%$ of the deviance, while genetic

342 background and its interaction with sex explained 2.2\% and 3.07\% (Figure 5). Mating

343 did not affect qualitative DCV shedding (Figure 3a; Table 5) and explained $<1 \%$ of

344 the deviance (Figure 5; Table 5). In flies where DCV was detected in shedding,

345 quantitative DCV shedding was affected by genetic background and the extent of

346 this variation was determined by female mating status, but not sex (Figure 3b; Table

347 6). The amount of variance explained by sex and in our models was $<1 \%$, in 348 comparison with genetic background (9.48\% and 5.82\%) and its interactions with sex

$349(8.87 \%)$ or mating (6.53\%) (Figure 5; Table 6). Qualitative and quantitative DCV

350 shedding peaked at day 2 (Figures 3a; Tables $5 \& 6$, pairwise comparisons, $351 \mathrm{p}<0.0001)$. Across all treatment groups, there was no significant relationship between

352 viral load and shedding (Figure S1; Table 6). 
(a)

(b)
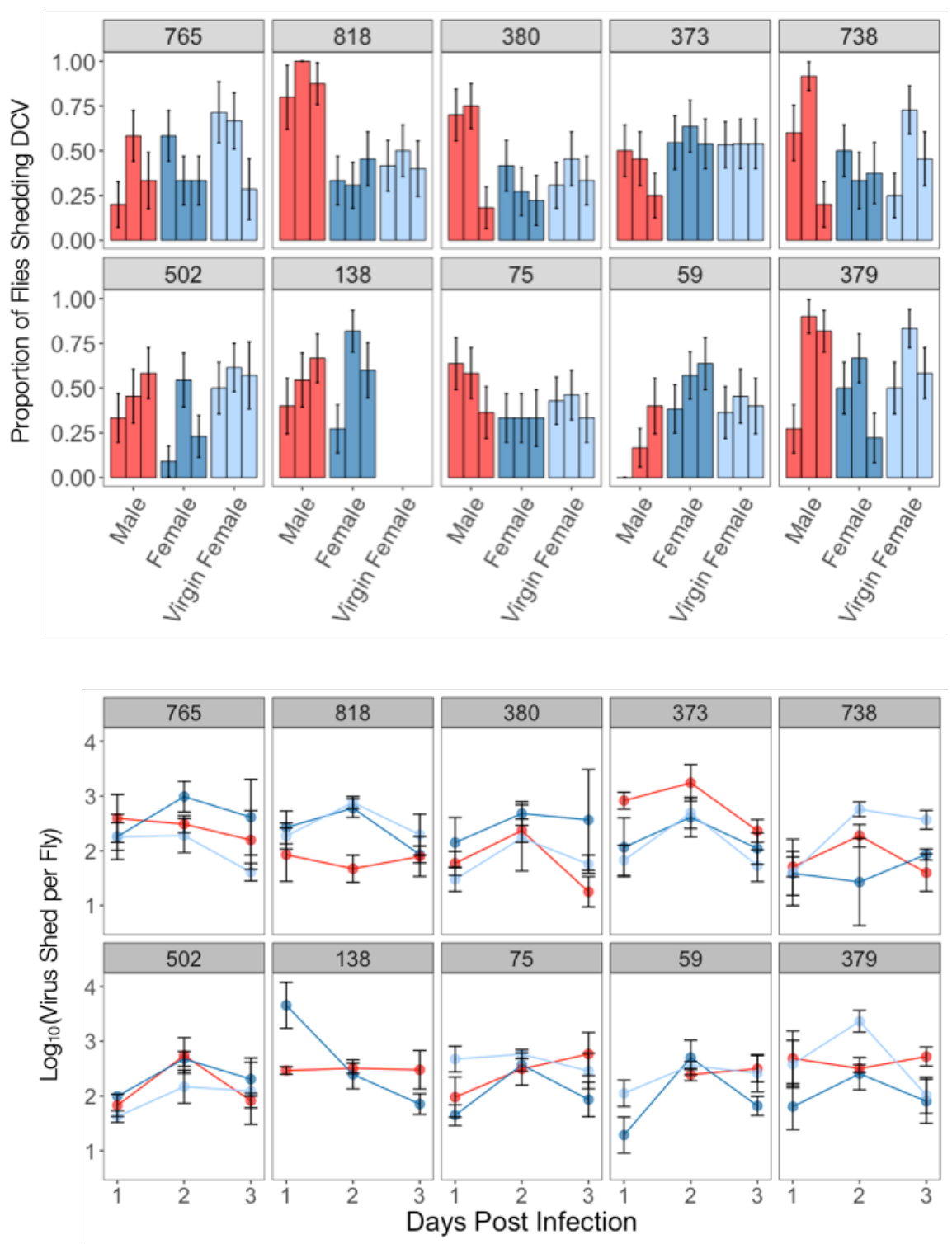

355 Figure 3. Mean \pm SE (a) proportion of flies shedding non-zero titres of DCV and the (b)

356 titre of the non-zero virus shedding subset over the first 3 days of infection. Panels

357 denote genetic background, while the colour of bars, points and lines represent sex

358 and mating status. Males are shown in red, mated females in blue, and virgin females

359 in pale blue. Bars of the same colour in each in pane in panel (a) represent (from left

360 to right) days 1, 2 and 3 of infection.

361

362 Variation in Transmission Potential, $V$

363 We incorporated the lifespan and virus shedding data described above alongside

364 previously gathered data on genetic and sex-specific variation in social aggregation 
365 to calculate individual disease transmission potential, $V$ (Lloyd-Smith et al., 2005;

366 VanderWaal \& Ezenwa, 2016). As a result of many flies not shedding DCV (Figure

367 3a), the distribution of transmission potential, $V$, was zero-inflated (Figure 4a). Zero

368 values of $V$ represent individuals with no transmission risk (Figure 4a), as flies that

369 shed no virus had no transmission potential, irrespective of their aggregation and

370 lifespan. The distribution of $V$ was also characterised by a right-extreme tail,

371 comprised of individuals with high-risk transmission potentials relative to the

372 population average (Figure 4a). Qualitative variation in $V$ (the proportion of flies where

373 b $>$ ) differed between males and females with the extent of this difference also

374 determined by genetic background (Figure 4b; Table 7). Sex (0.28\%), genetic

375 background (2.3\%) and the interaction between the two (2.83\%) explained relatively

376 little deviance in our models (Figure 5; Table 7). In quantitative variation in $V$, sex

377 explained $<1 \%$, while genetic background and its interaction with sex explained

$3784.13 \%$ and $11.4 \%$ of variance respectively (Figure 5; Table 8). 


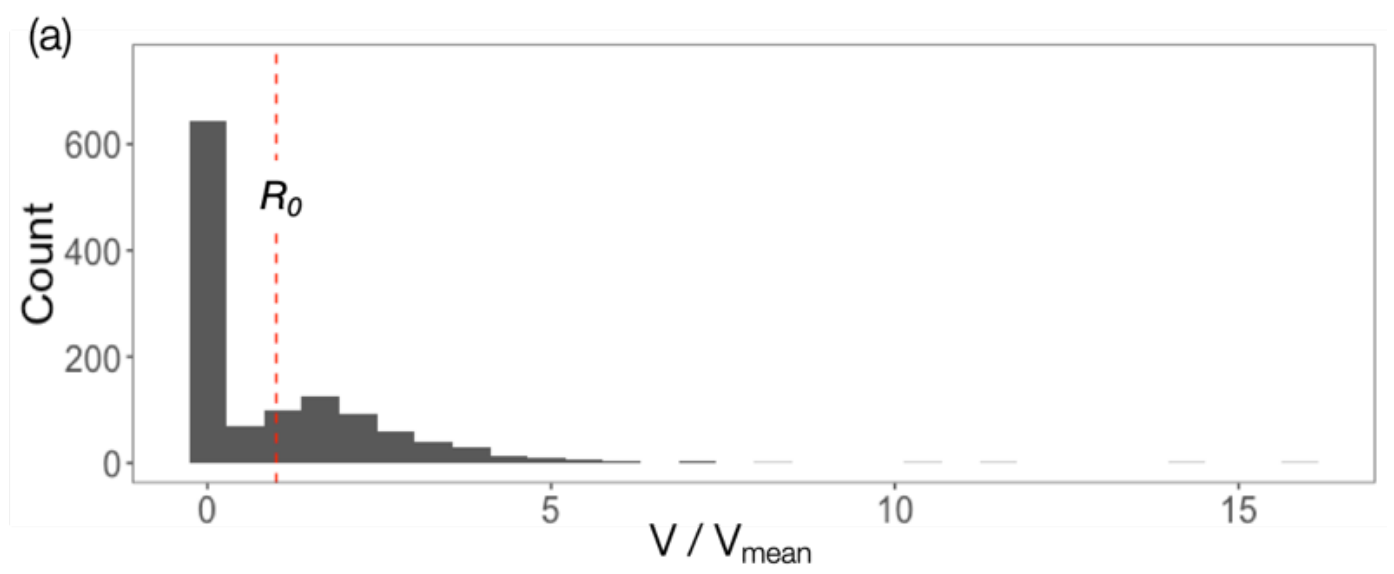

(b)

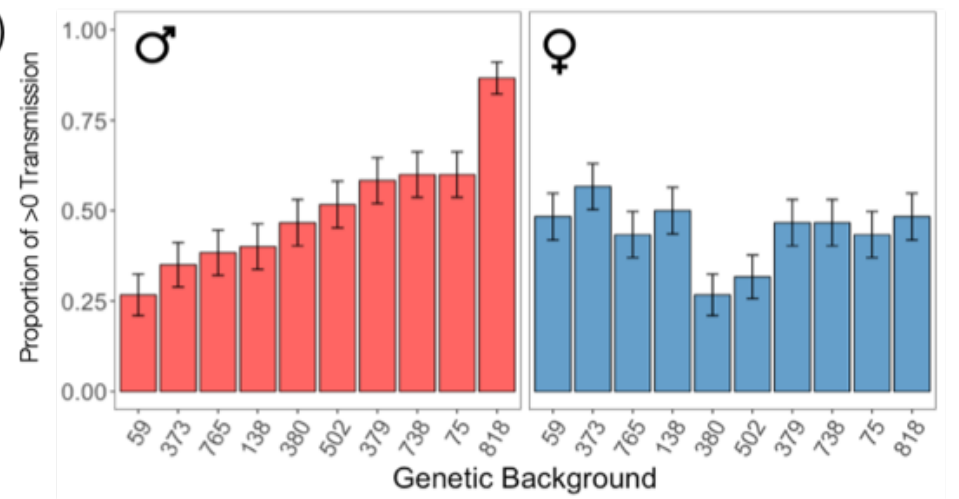

(c)

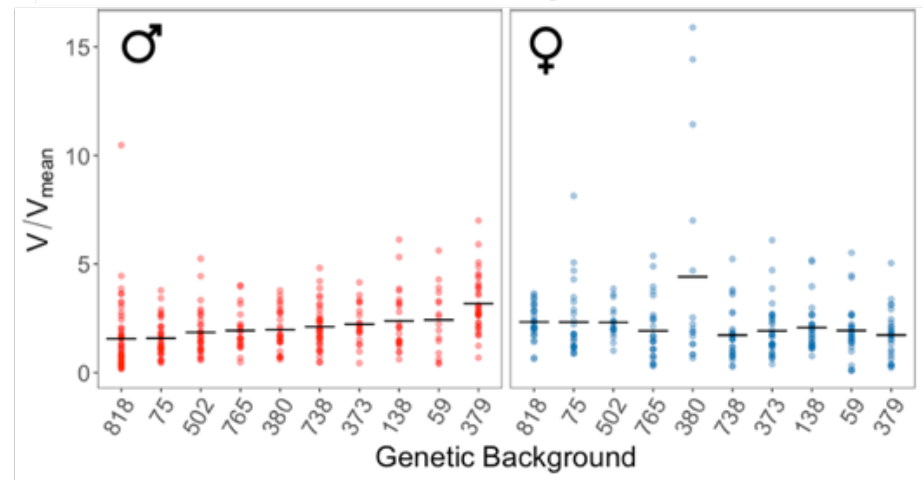

380 Figure 4. Bootstrap simulation results of transmission potential $(V)(n=60)$ : (a) the

381 population-level distribution of $V$ relative to the mean of the population. The red

382 dashed line demarcates the average transmission potential of the population (similar

383 to $R_{0}$ ), a traditional metric used to describe a population's outbreak risk. The

384 mean \pm SE of (b) the proportion of flies with a non-zero transmission potential and (c)

385 the transmission potential of flies with a non-zero transmission potential. In figure

386 panels (b) and (c) sex is denoted by colour with males in red and females in blue.

387 The $x$-axis of panels (b) and (c) is in ascending order of the male genetic 388 backgrounds. 


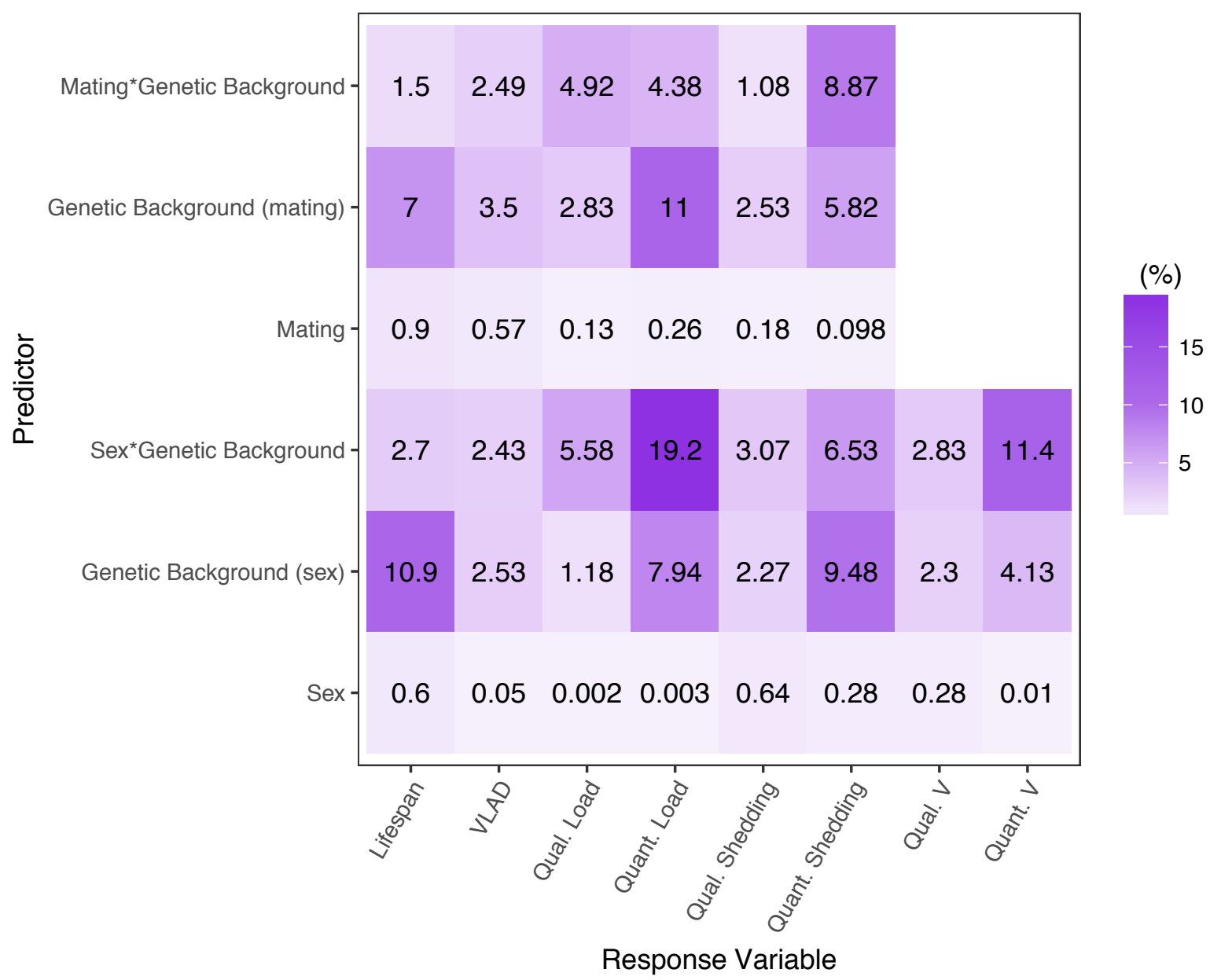

Figure 5. Summary of the percentage of variance or deviance explained by a subset

392 of predictors in analyses of disease transmission potential and outcomes of infection. 
Discussion

394 We identified genetic and sex-specific variation in three key outcomes of DCV

395 infection: lifespan following infection, virus shedding, and virus load. When combined

396 with social aggregation data, this variation resulted in genetic and sex-specific variation in individual transmission potential, $V$. While all of these outcomes of

398 infection influence transmission potential, due to many individuals not shedding any

399 virus, virus shedding exerted more influence over $\vee$ than variation in lifespan following infection and social aggregation. Due to this central role, below we discuss potential explanations for the effect of mating, as well as genetic and sex-specific variation on virus shedding, and link these to genetic and sex-specific variation in $V$.

403

\section{The effect of host genetic background in generating heterogeneity in transmission}

405 The genetic variation in virus shedding affected both qualitative and quantitative variation in DCV shedding. As the distributions of neither social aggregation nor

407 lifespan following infection were zero-inflated, variation in virus shedding appears to 408 be a key determinant of qualitative and quantitative variation in $V$. Differences 409 between genetic backgrounds in qualitative shedding was a key determinant of 410 variation in $\mathrm{V}$, as there is no risk of pathogen transmission in the absence of shedding. 411 Among individuals that shed DCV, between-individual heterogeneity in $V$ was 412 achieved through different routes. Some genetic backgrounds, such as males from 413 RAL-818, showed a high proportion of individuals that are likely to spread DCV 414 (Figure 4b), but only to relatively few individuals (Figure 4c). Conversely, other 415 groups, such as females of the RAL-380 genetic backgrounds, showed one of the 416 lowest proportions of individuals able to achieve transmission (Figure 4b), but the 417 individuals that did achieve transmission include outliers with values of $V$ that were 418 orders of magnitude higher than the population average (Figure 4c).

420 Quantitative and qualitative variation in DCV shedding differed in how they were 421 affected by host genetic background. Qualitative variation was affected by genetic 
422 background as part of an interaction with host sex, while this interaction has no

423 significant effect on quantitative DCV shedding (Tables 5 \& 6). Similar differences are

424 seen in the amount of deviance and variance genetic background explains in models

425 of qualitative and quantitative variation in DCV shedding. Genetic background 426 accounts for only $2.27 \%$ of deviance in qualitative DCV shedding whereas it accounts 427 for $9.48 \%$ of the variance in quantitative DCV shedding (Figure 5). Genetic variation 428 therefore appears to play an important role in determining shedding and affects 429 qualitative and quantitative shedding in different ways. Similar effects of genetic 430 backgrounds on parasite shedding have been reported in the Ramshorn snail 431 species, Biomphlamaria glabrata, during infection with Schistosoma mansoni. 432 Genetic backgrounds differ in how many parasite eggs they shed and how quickly 433 they start shedding after infection (Tavalire et al., 2016). The differences we see in 434 the proportion of flies shedding DCV may be caused by a similar pattern of variation 435 in individual's delaying virus shedding. Delaying the onset of shedding could be 436 affected by a range of DCV infection symptoms. These include paralysis of muscles 437 in the crop organ of the foregut, abdominal swelling, broad nutritional stress and 438 reduced defecation rate (Chtarbanova et al., 2014).

440 Genetic background also appears to play a key role in transmission potential, we detected a significant effect on both qualitative and quantitative variation in $V$. The

442 amount of deviance and variance explained by genetic background does not hugely 443 differ (2.3\% and 4.13\%, respectively). However, when part of an interaction with sex, 444 genetic background accounts for $11.4 \%$ of the variance in quantitative variation in 445 DCV shedding, whereas this same interaction only accounts for $2.83 \%$ of the 446 deviance in qualitative variation in shedding (Figure 5). Alongside other studies, this 447 highlights the potential significance of genetic variation in pathogen shedding to 448 generating transmission heterogeneity. For example, genetic variation in transmission 449 was demonstrated using families of turbot fish (Scophthalmus maximus) which 450 produced outbreaks that differed in how quickly individuals showed symptoms of 
451 infection and died (Anacleto et al., 2019). Shedding may underlie this genetic 452 variation in transmission as it was not directly measured and there were no 453 significant differences in infection duration and contact rate (Anacleto et al., 2019).

454 Common garden experiments have revealed shedding dynamics capable of 455 influencing the population-level transmission dynamics of wild populations of the plant, Plantago lanceolata. In controlled laboratory settings, multi-strain coinfection

457 was shown to increase the number of spores released of the fungal pathogen, 458 Podosphaera plantaginis. Measures of natural populations have also demonstrated 459 outbreak severity increases at higher levels of coinfection (Susi, Barrès, Vale, \& Laine, 460 2015). The relationship between spore shedding and coinfection has also been shown to be affected by host genotype, with genotypes significantly differing in the number of spores released over a number of days post-infection (Susi, Vale, \& Laine, 2015). Genetic variation in transmission potential has also been demonstrated in the freshwater ciliate, Paramecium caudatum, following Holospora undulata infection

465 (Fellous et al., 2012). The genotype of the first individual to be infected was a key determinant of pathogen transmission as host genotype appears to affect the infectious potential of shed pathogens (Fellous et al., 2012). H. undulata infectiousness increases with host population density, as reduced variation in contact rate makes infectiousness the primary determinant of transmission (Magalon et al., 2010).

473 We also observed clear qualitative and quantitative differences in $V$ between males and females, which is suggestive of sex-specific variation in disease transmission. While the extent of any difference between males and females is also determined by genetic background, a greater proportion of males tend to transmit DCV than females across

477 these backgrounds. In DCV shedding, a greater proportion of males from several genetic 478 backgrounds (RAL-379, RAL-738 and RAL-818) shed DCV than females (Figure 3a). 
479 Interestingly, we see significant sex-specific differences in qualitative, but not quantitative,

480 variation in DCV shedding. Other work has also shown a number of sex differences in

481 pathogen and parasite shedding (Sanchez, Devevey, \& Bize, 2011; Sheridan, Poulin,

482 Ward, \& Zuk, 2000; Thompson, Gipson, \& Hall, 2017). Often these biases link to

483 differences in the selection pressures applied by sexual reproduction (Duneau \& Ebert,

484 2012). Comparisons of mated and virgin female flies revealed mating effects which

485 produced quantitative, but not qualitative, differences in shedding. While we did not

486 measure $V$ in virgin females, this mating effect may offer explanations for the sex

487 differences seen in shedding and therefore $V$.

488

489 Sex-specific variation in qualitative differences in shedding exerts a significant influence

490 over shedding (Figure 3a). It is important to note however, that in isolation, sex accounts

491 for a miniscule $0.64 \%$ of the deviance in qualitative variation in shedding. Sex appears to

492 play a more important role in conjunction with genetic background, the interaction

493 between the two explaining 3.07\% of deviance (Figure 5). While significant, sex-specific

494 variation may play a relatively minor role in shedding. A variety of factors appear to

495 underlie sex-differences in shedding across host-pathogen systems. For example, male-

496 biased infection is common to many mammal hosts but generally absent from arthropod

497 hosts (Sheridan et al., 2000). In the water flea, Daphnia magna, parasite spores are

498 released into the environment upon death and females have been shown to release

499 significantly more than males (Thompson et al., 2017). In the vole, Microtus gryalis, the

500 faeces of females contains significantly more parasite eggs than that of males (Sanchez

501 et al., 2011). Given that we see female-biased mortality to DCV infection (Figure 1a), it is

502 perhaps surprising that shedding is not also female-biased. This could be due to 
shedding being measured during the first three days of infection, whereas mortality

504 occurred much later. We might therefore see sex-differences in shedding during the later stages of infection.

507 Both the qualitative and quantitative differences in $V$ between males and females were

508 determined alongside genetic background. While sex explained very little deviance and

509 variance in qualitative and quantitative variation in $V$ (Figure 6), its interaction with genetic

510 background explained $2.83 \%$ and $11.4 \%$, respectively. Sex could therefore be an

511 important source of variation in individual disease transmission. Sex differences in

512 transmission or virus shedding, lifespan and social aggregation are commonly observed

513 in a wide range of species (Duneau \& Ebert, 2012; Ferrari, Cattadori, Nespereira, Rizzoli,

514 \& Hudson, 2004; Kaltz \& Shykoff, 2001; Sanchez et al., 2011). Sex-specific variation has

515 been relatively well-studied because sexes are easily distinguished in the wild, and

516 examples of sexual dimorphism in physiological and behavioural traits are relatively

517 common (Duneau and Ebert, 2012). Many mammalian hosts exhibit male-biased

518 transmission (Ezenwa et al., 2016; Grear, Luong, \& Hudson, 2012; Luong, Grear, \&

519 Hudson, 2009; Rhines, 2013), although there are exceptions of female-bias (Sanchez et

520 al., 2011). In the white-footed mouse, Peromyscus leucopus, male-biased transmission

521 is thought to be driven by sex differences in contact network connectivity, which has

522 been linked to testosterone production (Foo, Nakagawa, Rhodes, \& Simmons, 2017;

523 Grear et al., 2012). Testosterone may be particularly relevant to transmission as its

524 immunosuppressive (Foo et al., 2017) effects may also alter infectiousness and infection 525 duration. 
$527 \quad$ Female Mating Status in Shedding

528 Mated and virgin females did not qualitatively differ in DCV shedding; however, individuals

529 did exhibit quantitative variation in shedding. While only $0.098 \%$ of the variance in

530 quantitative shedding was explained by mating, the interaction between mating and

531 genetic background explained $8.87 \%$ of the variance (Figure 5). This suggests that

532 alongside host genetic background, mating might exert an important level of influence

533 over shedding. One potential explanation for this mating effect are post-mating

534 physiological changes in the intestine that can increase in defecation rates (Apger-

535 McGlaughon and Wolfner, 2013). However, if this change is responsible for the significant

536 effect of female mating, the virgin females from particular genetic backgrounds that shed

537 more than mated females (Figure 3b) may be tolerant to these physiological changes.

538 Relatively few have considered how mating affects aspects of disease transmission

539 outside of contact rates (Altizer et al., 2003; Thrall et al., 2000). Particularly alongside

540 other work in Drosophila that has demonstrated female-specific costs of infection (Kubiak

541 and Tinsley, 2017; Short et al., 2012), this result highlights the importance of mating-

542 induced physiological changes to transmission heterogeneity.

544 The difference between qualitative and quantitative variation in shedding relates to

545 assumptions we make regarding how often DCV is shed. If DCV is always present in

546 shedding, measures of zero reflect quantities of virus that are below the detection

547 threshold of qPCR. While this could result in infectious individuals evading detection, as

548 oral infection typically requires very high dosage (Gupta et al., 2017; Palmer et al., 2018),

549 low-titre zero-values pose a smaller transmission risk. If DCV is not always shed, within-

550 individual variation in when shedding occurs could be central to transmission 
551 heterogeneity (Chen, Sanderson, \& Lanzas, 2013). This is particularly relevant to our

552 study as virus shedding was only measured at a single time point per fly, and we do

553 not know how shedding, and therefore $V$, may change over time. Within-host, temporal

554 variation in shedding is observed in a range of host-pathogen systems (Chen et al.,

555 2013; Matthews et al., 2006; Mideo, Alizon, \& Day, 2008). For example, avian hosts

556 tend to shed more parasites during the late afternoon (Brawner III and Hill, 1999;

557 Martinaud et al., 2009).

558

559 By combining measures of virus shedding, lifespan and social aggregation into a simple

560 framework our work demonstrates that genetic and sex-specific variation can affect

561 individual heterogeneity in disease transmission potential. We also show that genetic and

562 sex-specific variation, as well as mating, can produce variation outcomes of infection.

563 Alongside its interaction with sex, genetic background explains $5.41 \%$ of qualitative, and

$56415.54 \%$ of quantitative, individual variation in transmission potential. While our results do

565 not implicate a particular genetic background, males generally present a greater

566 transmission risk than females. In addition to highlighting high-risk individuals, our results

567 are congruous with the observation that the majority of infected individuals produce very

568 few, if any, secondary cases of infection. Non-infectious individuals are particularly

569 relevant to predicting outbreaks of infectious disease as they obscure high-risk

570 individuals in traditional, population-wide estimations of outbreak risk. Our findings

571 demonstrate the benefit of using a model laboratory system as well established as $D$.

572 melanogaster to study disease transmission. The number of available protocols and

573 methodologies are central to considering multiple traits central to disease transmission

574 and holistically studying their underlying determinants. 


\section{Acknowledgements}

576 J.A.S-J was funded by a NERC E3 DTP PhD studentship awarded to the University of

577 Edinburgh. P.F.V was supported by a Branco Weiss fellowship

578 (https://brancoweissfellowship.org/) and a Chancellor's Fellowship (School of Biological

579 Sciences, University of Edinburgh).

580

581 We would like to thank F. Waldron for assistance with RNA extraction and

582 troubleshooting as well as V. Gupta, K. Monteith, H. Borthwick, H. Cowan, and A. Reid

583 for technical assistance and media preparation. 
References

Altizer, S., Nunn, C. L., Thrall, P. H., Gittleman, J. L., Antonovics, J., Cunningham, A. A., ... Pulliam, J. R. C. (2003). Social organization and parasite risk in mammals: Integrating theory and empirical studies. Annual Review of Ecology Evolution and Systematics, 34, 517-547. doi: 10.1146/annurev.ecolsys.34.030102.151725

Apger-McGlaughon, J., \& Wolfner, M. F. (2013). Post-mating change in excretion by mated Drosophila melanogaster females is a long-term response that depends on sex peptide and sperm. Journal of Insect Physiology, 59(10), 1024-1030. doi: 10.1016/j.jinsphys.2013.07.001

Apidianakis, Y., \& Rahme, L. G. (2009). Drosophila melanogaster as a model host for studying Pseudomonas aeruginosa infection. Nature Protocols, 4(9), 1285-1294. doi: $10.1038 /$ nprot.2009.124

Arnold, P. A., Johnson, K. N., \& White, C. R. (2013). Physiological and metabolic 605

Bates, D., Mächler, M., Bolker, B., \& Walker, S. (2015). Fitting Linear Mixed-Effects Models Using Ime4. Journal of Statistical Software, 67(1). doi: 10.18637/jss.v067.i01

606 Beldomenico, P. M., \& Begon, M. (2010). Disease spread, susceptibility and infection intensity: vicious circles? Trends in Ecology \& Evolution, 25(1), 21-27. doi: 
609 Bolzoni, L., Real, L., \& Leo, G. D. (2007). Transmission Heterogeneity and Control

612 Bou Sleiman, M. S., Osman, D., Massouras, A., Hoffmann, A. A., Lemaitre, B., \&

Brawner III, W. R., \& Hill, G. E. (1999). Temporal variation in shedding of coccidial oocysts: implications for sexual-selection studies. Canadian Journal of Zoology,

619 Brooks-Pollock, E., Roberts, G. O., \& Keeling, M. J. (2014). A dynamic model of bovine tuberculosis spread and control in Great Britain. Nature, 511(7508), 228-231. doi:

Budischak, S. A., Sakamoto, K., Megow, L. C., Cummings, K. R., Urban, J. F., \& Ezenwa, V. O. (2015). Resource limitation alters the consequences of co-infection for both hosts and parasites. International Journal for Parasitology, 45(7), 455-463. doi: Mason, W. A. (2008). Personality and serotonin transporter genotype interact with social context to affect immunity and viral set-point in simian immunodeficiency virus disease. Brain, Behavior, and Immunity, 22(5), 676-689. doi:

631 Centers for Disease Control and Prevention (CDC). (2003). Severe acute respiratory syndrome--Singapore, 2003. MMWR. Morbidity and Mortality Weekly Report, 52(18), 405-411. 
634 Chen, S., Sanderson, M., \& Lanzas, C. (2013). Investigating effects of between- and withinhost variability on Escherichia coli O157 shedding pattern and transmission. Preventive Veterinary Medicine, 109(1), 47-57. doi: 10.1016/j.prevetmed.2012.09.012

Chtarbanova, S., Lamiable, O., Lee, K.-Z., Galiana, D., Troxler, L., Meignin, C., ... Imler, J.L. (2014). Drosophila C virus systemic infection leads to intestinal obstruction. Journal of Virology, 88(24), 14057-14069. doi: 10.1128/JVI.02320-14

641 Cornet, S., Bichet, C., Larcombe, S., Faivre, B., \& Sorci, G. (2014). Impact of host nutritional status on infection dynamics and parasite virulence in a bird-malaria system. The Journal of Animal Ecology, 83(1), 256-265. doi: 10.1111/13652656.12113

de Bono, M., \& Bargmann, C. I. (1998). Natural variation in a neuropeptide Y receptor

Duneau, D., \& Ebert, D. (2012). Host Sexual Dimorphism and Parasite Adaptation. PLOS Biology, 10(2), e1001271. doi: 10.1371/journal.pbio.1001271 White, L. (2016). Host behaviour-parasite feedback: an essential link between animal behaviour and disease ecology. Proc. R. Soc. B, 283(1828), 20153078-20153078. doi:

654 Farrington, C. P., Whitaker, H. J., Unkel, S., \& Pebody, R. (2013). Correlated Infections: 
657 Fellous, S., Duncan, A. B., Quillery, E., Vale, P. F., \& Kaltz, O. (2012). Genetic influence on

658

659

660

661

662

663

664

665

666

667

668

669

670

671

672

673

674

675

676

677

678

679

680 disease spread following arrival of infected carriers. Ecology Letters, 15(3), 186-192. doi: 10.1111/j.1461-0248.2011.01723.x

Ferrari, N., Cattadori, I. M., Nespereira, J., Rizzoli, A., \& Hudson, P. J. (2004). The role of host sex in parasite dynamics: field experiments on the yellow-necked mouse Apodemus flavicollis. Ecology Letters, 7(2), 88-94. doi: 10.1046/j.14610248.2003.00552.x

Foo, Y. Z., Nakagawa, S., Rhodes, G., \& Simmons, L. W. (2017). The effects of sex hormones on immune function: a meta-analysis. Biological Reviews, 92(1), 551-571. doi: $10.1111 /$ brv. 12243

Gervasi, S. S., Civitello, D. J., Kilvitis, H. J., \& Martin, L. B. (2015). The context of host competence: A role for plasticity in host-parasite dynamics. Trends in Parasitology, 31(9), 419-425. doi: 10.1016/j.pt.2015.05.002

Godfrey, S. S. (2013). Networks and the ecology of parasite transmission: A framework for wildlife parasitology. International Journal for Parasitology: Parasites and Wildlife, 2, 235-245. doi: 10.1016/j.ijppaw.2013.09.001

Grassly, N. C., \& Fraser, C. (2008). Mathematical models of infectious disease transmission. Nature Reviews. Microbiology, 6(3), 234-244. doi: 10.1038/nrmicro1845

Grear, D. A., Luong, L. T., \& Hudson, P. J. (2012). Sex-biased transmission of a complex life-cycle parasite: why males matter. Oikos, 121(9), 1446-1453. doi: 10.1111/j.16000706.2012.20358.x

Gupta, V., Stewart, C., Rund, S. S. C., Monteith, K., \& Vale, P. F. (2017). Costs and benefits of sub-lethal Drosophila C virus infection. Journal of Evolutionary Biology. doi: 10.1111/jeb.13096 
681 Hothorn, T., Bretz, F., \& Westfall, P. (2008). Simultaneous Inference in General Parametric

682

683

684

685

686

687

688

689

690

691

692

693

694

695

696

697

698

699

700

701

702

703

Models. Biometrical Journal, 50(3), 346-363.

Kaltz, O., \& Shykoff, J. A. (2001). Male and female Silene latifolia plants differ in percontact risk of infection by a sexually transmitted disease. Journal of Ecology, 89(1), 99-109. doi: 10.1046/j.1365-2745.2001.00527.x

Keeling, M. J., \& Rohani, P. (2007). Chapter One Contact Tracing Operates by Refining the Targeting of Other Control Measures. 1.4. What Are Mathematical Models?

Keiser, C. N., Howell, K. A., Pinter-Wollman, N., Pruitt, J. N., Woolhouse, ME., Kortet, R., ... Edelstein-Keshet, L. (2016). Personality composition alters the transmission of cuticular bacteria in social groups. Biology Letters, 12(7), 338-342. doi:

$10.1098 / \mathrm{rsbl} .2016 .0297$

Keiser, C. N., Pinter-Wollman, N., Augustine, D. A., Ziemba, M. J., Hao, L., Lawrence, J. G., \& Pruitt, J. N. (2016). Individual differences in boldness influence patterns of social interactions and the transmission of cuticular bacteria among group-mates. Proceedings of the Royal Society B: Biological Sciences, 283(1829), 2016045720160457. doi: 10.1098/rspb.2016.0457

Kubiak, M., \& Tinsley, M. C. (2017). Sex-Specific Routes To Immune Senescence In Drosophila melanogaster. Scientific Reports, 7(1), 10417. doi: 10.1038/s41598-017$11021-6$

Lass Sandra, Hudson Peter J., Thakar Juilee, Saric Jasmina, Harvill Eric, Albert Réka, \& Perkins Sarah E. (2013). Generating super-shedders: co-infection increases bacterial load and egg production of a gastrointestinal helminth. Journal of The Royal Society Interface, 10(80), 20120588. doi: 10.1098/rsif.2012.0588 
704

705

706

707

708

709

710

711

712

713

714

715

716

717

718

719

720

721

722

723

724

725

726

727

Lazzaro Brian P, \& Little Tom J. (2009). Immunity in a variable world. Philosophical Transactions of the Royal Society B: Biological Sciences, 364(1513), 15-26. doi: $10.1098 /$ rstb.2008.0141

Li, Y., Yu, I. T. S., Xu, P., Lee, J. H. W., Wong, T. W., Ooi, P. L., \& Sleigh, A. C. (2004). Predicting super spreading events during the 2003 severe acute respiratory syndrome epidemics in Hong Kong and Singapore. American Journal of Epidemiology, 160(8), 719-728. doi: 10.1093/aje/kwh273

Life Technologies. (2011). MagMAX-96 Total RNA Isolation Kit User Guide. Carlsbad, CA USA: Life Technologies Corporation.

Lloyd-Smith, J. O., Schreiber, S. J., Kopp, P. E., Getz, W. M., Schreiber, SJ., Kopp, PE., ... Kjelvik, MK. (2005). Superspreading and the effect of individual variation on disease emergence. Nature, 438(7066), 355-359. doi: 10.1038/nature04153

Luong, L. T., Grear, D. A., \& Hudson, P. J. (2009). Male hosts are responsible for the transmission of a trophically transmitted parasite, Pterygodermatites peromysci, to the intermediate host in the absence of sex-biased infection. International Journal for Parasitology, 39(11), 1263-1268. doi: 10.1016/j.ijpara.2009.03.007

Magalon, H., Nidelet, T., Martin, G., \& Kaltz, O. (2010). Host growth conditions influence experimental evolution of life history and virulence of a parasite with vertical and horizontal transmission. Evolution; International Journal of Organic Evolution, 64(7), 2126-2138. doi: 10.1111/j.1558-5646.2010.00974.x

Magwire, M. M., Fabian, D. K., Schweyen, H., Cao, C., Longdon, B., Bayer, F., \& Jiggins, F. M. (2012). Genome-Wide Association Studies Reveal a Simple Genetic Basis of Resistance to Naturally Coevolving Viruses in Drosophila melanogaster. PLoS Genetics, 8(11). doi: 10.1371/journal.pgen.1003057 
Marineli, F., Tsoucalas, G., Karamanou, M., \& Androutsos, G. (2013). Mary Mallon (1869-

Martinaud, G., Billaudelle, M., \& Moreau, J. (2009). Circadian variation in shedding of the oocysts of Isospora turdi (Apicomplexa) in blackbirds (Turdus merula): An adaptative trait against desiccation and ultraviolet radiation. International Journal for Parasitology, 39(6), 735-739. doi: 10.1016/j.ijpara.2008.11.006

Matthews, L., Low, J. C., Gally, D. L., Pearce, M. C., Mellor, D. J., Heesterbeek, J. a P., ... Woolhouse, M. E. J. (2006). Heterogeneous shedding of Escherichia coli O157 in cattle and its implications for control. Proceedings of the National Academy of Sciences of the United States of America, 103(3), 547-552. doi: 10.1073/pnas.0503776103

Mideo, N., Alizon, S., \& Day, T. (2008). Linking within- and between-host dynamics in the evolutionary epidemiology of infectious diseases. Trends in Ecology \& Evolution, 23(9), 511-517. doi: 10.1016/j.tree.2008.05.009

Palmer, W. H., Medd, N. C., Beard, P. M., \& Obbard, D. J. (2018). Isolation of a natural DNA virus of Drosophila melanogaster, and characterisation of host resistance and immune responses. PLOS Pathogens, 14(6), e1007050. doi: 10.1371/journal.ppat.1007050

Patterson, J. E. H., \& Ruckstuhl, K. E. (2013). Parasite infection and host group size: a metaanalytical review. Parasitology, 140(7), 803-813. doi: 10.1017/S0031182012002259 (2011). From superspreaders to disease hotspots: linking transmission across hosts and space. Frontiers in Ecology and the Environment, 10(2), 75-82. doi: $10.1890 / 110111$ 
Paull, S. H., Song, S., McClure, K. M., Sackett, L. C., Kilpatrick, A. M., \& Johnson, P. T. J. and space. Frontiers in Ecology and the Environment, 10(2), 75-82. doi:

$$
10.1890 / 110111
$$

Ponton, F., Wilson, K., Holmes, A. J., Cotter, S. C., Raubenheimer, D., \& Simpson, S. J. (2013). Integrating nutrition and immunology: A new frontier. Journal of Insect Physiology, 59(2), 130-137. doi: 10.1016/j.jinsphys.2012.10.011

Rhines, A. S. (2013). The role of sex differences in the prevalence and transmission of tuberculosis. Tuberculosis, 93(1), 104-107. doi: 10.1016/j.tube.2012.10.012

Rushmore, J., Caillaud, D., Matamba, L., Stumpf, R. M., Borgatti, S. P., \& Altizer, S. (2013). Social network analysis of wild chimpanzees provides insights for predicting infectious disease risk. Journal of Animal Ecology, 82(5), 976-986. doi: $10.1111 / 1365-2656.12088$ CHOICE: CONTEXT-DEPENDENT GENE-ENVIRONMENT CORRELATION IN DROSOPHILA MELANOGASTER. Evolution, 65(8), 2325-2334. doi: the gastrointestinal nematode Trichuris arvicolae infecting the common vole, Microtus arvalis. International Journal for Parasitology, 41(13), 1397-1402. doi: 10.1016/j.ijpara.2011.09.004 wildlife populations: a quantitative review. Parasitology, 111(S1), S111-S133. doi: $10.1017 / \mathrm{S} 0031182000075855$ 
Sheridan, L. A. D., Poulin, R., Ward, D. F., \& Zuk, M. (2000). Sex differences in parasitic infections among arthropod hosts: is there a male bias? Oikos, 88(2), 327-334. doi: 10.1034/j.1600-0706.2000.880211.x

Short, S. M., Wolfner, M. F., \& Lazzaro, B. P. (2012). Female Drosophila melanogaster suffer reduced defense against infection due to seminal fluid components. Journal of Insect Physiology, 58(9), 1192-1201. doi: 10.1016/j.jinsphys.2012.06.002

Siva-Jothy, J. A., \& Vale, P. F. (2019). Viral infection causes sex-specific changes in fruit fly social aggregation behaviour. BioRxiv, 630913. doi: 10.1101/630913

Sokolowski, M. B. (2001). Drosophila: genetics meets behaviour. Nature Reviews. Genetics, 2(11), 879-890. doi: 10.1038/35098592

Stein, R. A. (2011). Super-spreaders in infectious diseases. International Journal of Infectious Diseases : IJID : Official Publication of the International Society for Infectious Diseases, 15(8), e510-3. doi: 10.1016/j.ijid.2010.06.020

Susi, H., Barrès, B., Vale, P. F., \& Laine, A.-L. (2015). Co-infection alters population dynamics of infectious disease. Nature Communications, 6, 5975. doi: 10.1038/ncomms6975

Susi, H., Vale, P. F., \& Laine, A.-L. (2015). Host Genotype and Coinfection Modify the Relationship of within and between Host Transmission. The American Naturalist, 186(2), 000-000. doi: 10.1086/682069

Tavalire, H. F., Blouin, M. S., \& Steinauer, M. L. (2016). Genotypic variation in host response to infection affects parasite reproductive rate. International Journal for Parasitology, 46(2), 123-131. doi: 10.1016/j.ijpara.2015.10.001

Thompson, O., Gipson, S. A. Y., \& Hall, M. D. (2017). The impact of host sex on the outcome of co-infection. Scientific Reports, 7(1), 910. doi: 10.1038/s41598-017$00835-\mathrm{z}$ 
Thrall, P. H., Antonovics, J., \& Dobson, A. P. (2000). Sexually transmitted diseases in polygynous mating systems: prevalence and impact on reproductive success. Proceedings of the Royal Society B: Biological Sciences, 267(1452), 1555-1563.

Vale, P. F., Choisy, M., \& Little, T. J. (2013). Host nutrition alters the variance in parasite transmission potential. Biology Letters, 9(2). doi: 10.1098/rsbl.2012.1145

Vale, P. F., \& Jardine, M. D. (2015). Sex-specific behavioural symptoms of viral gut infection and Wolbachia in Drosophila melanogaster. Journal of Insect Physiology, 82, 28-32. doi: 10.1016/j.jinsphys.2015.08.005

810 VanderWaal, K. L., \& Ezenwa, V. O. (2016). Heterogeneity in pathogen transmission: mechanisms and methodology. Functional Ecology, n/a-n/a. doi: 10.1111/13652435.12645

813 White, L. A., Forester, J. D., \& Craft, M. E. (2018). Covariation between the physiological and behavioral components of pathogen transmission: host heterogeneity determines

816 Wickham, H. (2016). ggplot2: Elegant Graphics for Data Analysis. Springer-Verlag New York. Skorping, A. (2002). Chapter 2: Heterogeneities in macroparasite infections: patterns and processes. The Ecology of Wildlife Diseases. Oxfor University Press, Oxford, 6-

822 Woolhouse, M. E. J., Dye, C., Etard, J.-F., Smith, T., Charlwood, J. D., Garnett, G. P., ... Anderson, R. M. (1997). Heterogeneities in the transmission of infectious agents : Proceedings of the National Academy of Sciences of the United States of America, 94(January), 338-342. 


\begin{tabular}{|c|c|c|c|c|c|}
\hline $\begin{array}{l}\text { Response } \\
\text { Variable }\end{array}$ & Predictor & $\overline{\mathrm{Df}}$ & $\bar{F}$ & $\begin{array}{l}\text { \%Variance } \\
\text { Explained }\end{array}$ & p-value \\
\hline \multirow{14}{*}{$\begin{array}{l}\text { Lifespan } \\
\text { Following } \\
\text { Infection }\end{array}$} & Sex & 1 & 2.00 & 0.6 & 0.16 \\
\hline & Genetic Background & 9 & 3.92 & 10.9 & $<0.0001$ \\
\hline & VLAD & 1 & 38.9 & 12.1 & $<0.0001$ \\
\hline & $\begin{array}{l}\text { Sex }{ }^{\star} \text { Genetic } \\
\text { Background }\end{array}$ & 9 & 0.96 & 2.7 & 0.47 \\
\hline & Sex ${ }^{\star} V L A D$ & 1 & 5.46 & 1.7 & 0.02 \\
\hline & $\begin{array}{l}\text { Genetic } \\
\text { Background*VLAD }\end{array}$ & 9 & 0.63 & 1.8 & 0.77 \\
\hline & $\begin{array}{l}\text { Sex*Genetic } \\
\text { Background }{ }^{\star} \text { LLAD }\end{array}$ & 9 & 2.67 & 7.4 & 0.005 \\
\hline & Mating & 1 & 2.74 & 0.9 & 0.099 \\
\hline & Genetic Background & 8 & 2.43 & 7.0 & 0.01 \\
\hline & VLAD & 1 & 32.3 & 10.2 & $<0.0001$ \\
\hline & $\begin{array}{l}\text { Mating }{ }^{\star} \text { Genetic } \\
\text { Background }\end{array}$ & 8 & 0.54 & 1.5 & 0.84 \\
\hline & Mating ${ }^{\star} V L A D$ & 1 & 3.78 & 1.2 & 0.053 \\
\hline & $\begin{array}{l}\text { Genetic } \\
\text { Background*VLAD }\end{array}$ & 8 & 1.71 & 4.9 & 0.087 \\
\hline & $\begin{array}{l}\text { Mating*Genetic } \\
\text { Background*VLAD }\end{array}$ & 8 & 1.46 & 4.2 & 0.16 \\
\hline
\end{tabular}

828

829 Table 1. Model outputs for the generalized linear modelling tests performed on

830 lifespan following DCV infection. The VLAD acronym is used in place of 'viral load at

831 death'. Separate analyses were used to test the effect of sex and mating in females. 


\begin{tabular}{|c|c|c|c|c|c|}
\hline $\begin{array}{l}\text { Response } \\
\text { Variable }\end{array}$ & Predictor & $\overline{D f}$ & $\bar{F}$ & $\begin{array}{l}\text { \% Variance } \\
\text { Explained }\end{array}$ & p-value \\
\hline \multirow{6}{*}{$\begin{array}{l}\text { Viral Load at } \\
\text { Death (VLAD) }\end{array}$} & Sex & 1 & 0.17 & 0.05 & 0.68 \\
\hline & $\begin{array}{l}\text { Genetic } \\
\text { Background }\end{array}$ & 9 & 0.96 & 2.53 & 0.47 \\
\hline & $\begin{array}{l}\text { Sex*Genetic } \\
\text { Background }\end{array}$ & 9 & 0.92 & 2.43 & 0.50 \\
\hline & Mating & 1 & 1.90 & 0.57 & 0.17 \\
\hline & $\begin{array}{l}\text { Genetic } \\
\text { Background }\end{array}$ & 8 & 1.30 & 3.5 & 0.24 \\
\hline & $\begin{array}{l}\text { Mating*Genetic } \\
\text { Background }\end{array}$ & 8 & 0.93 & 2.49 & 0.50 \\
\hline
\end{tabular}

833

834 Table 2. Model outputs for the generalized linear modelling tests performed on the

835 viral load at death of flies infected with DCV. Separate analyses were used to test the

836 effect of sex and mating in females.

837

\begin{tabular}{llcccc}
\hline $\begin{array}{c}\text { Response } \\
\text { Variable }\end{array}$ & \multicolumn{1}{c}{ Predictor } & Df & X $^{2}$ & $\begin{array}{c}\text { \% Deviance } \\
\text { Explained }\end{array}$ & $p$-value \\
\hline & Sex & 1 & 0.019 & 0.002 & 0.89 \\
& $\begin{array}{l}\text { Genetic } \\
\text { Background }\end{array}$ & 9 & 9.58 & 1.18 & 0.39 \\
& DPI & 2 & 36.6 & 4.52 & $<0.0001$ \\
& $\begin{array}{l}\text { Sex*Genetic } \\
\text { Background }\end{array}$ & 9 & 45.2 & 5.58 & $<0.0001$ \\
\cline { 2 - 6 } $\begin{array}{l}\text { Qualitative } \\
\text { DCV Load }\end{array}$ & Mating & 1 & 1.01 & 0.13 & 0.31 \\
& $\begin{array}{l}\text { Genetic } \\
\text { Background }\end{array}$ & 8 & 22.4 & 2.83 & 0.008 \\
& $\begin{array}{l}\text { DPI } \\
\text { Mating*Genetic } \\
\text { Background }\end{array}$ & 8 & 39.0 & 4.92 & $<0.0001$ \\
\hline
\end{tabular}

839 Table 3. Model outputs for the binomial logistic regression conducted on qualitative

840 DCV loads (the proportion of non-zero DCV loads). The DPI acronym is used in place

841 of 'days post-infection'. Separate analyses were used to test the effect of sex and 842 mating in females. 


\begin{tabular}{clcccc}
\hline $\begin{array}{c}\text { Response } \\
\text { Variable }\end{array}$ & \multicolumn{1}{c}{ Predictor } & DF & F & $\begin{array}{c}\text { \% Variance } \\
\text { Explained }\end{array}$ & p-value \\
\hline & Sex & 1 & 0.0062 & 0.003 & 0.94 \\
& $\begin{array}{l}\text { Genetic } \\
\text { Background } \\
\text { DPI }\end{array}$ & 9 & 2.24 & 7.94 & 0.02 \\
& $\begin{array}{l}\text { Sex* Genetic } \\
\text { Background }\end{array}$ & 9 & 5.41 & 19.2 & 0.036 \\
\cline { 2 - 6 } $\begin{array}{c}\text { Quating } \\
\text { DCV Load }\end{array}$ & Mating & 1 & 0.68 & 0.26 & 0.41 \\
& $\begin{array}{l}\text { Genetic } \\
\text { Background }\end{array}$ & 8 & 3.18 & 11.0 & 0.0012 \\
& $\begin{array}{l}\text { DPI } \\
\text { Mating* }\end{array}$ & 2 & 4.66 & 3.60 & 0.01 \\
& $\begin{array}{l}\text { Genetic } \\
\text { Background }\end{array}$ & 8 & 1.42 & 4.38 & 0.19 \\
\hline
\end{tabular}

844

845 Table 4. Model outputs for the GLM analysis conducted on quantitative DCV load (the

846 titres of non-zero DCV loads). The DPI acronym is used in place of 'days post-

847 infection'. Separate analyses were used to test the effect of sex and mating in

848 females. 


\begin{tabular}{|c|c|c|c|c|c|}
\hline $\begin{array}{l}\text { Response } \\
\text { Variable }\end{array}$ & Predictor & Df & $x^{2}$ & $\begin{array}{l}\text { \% Deviance } \\
\text { Explained }\end{array}$ & p-value \\
\hline \multirow{10}{*}{$\begin{array}{c}\text { Qualitative } \\
\text { DCV } \\
\text { Shedding }\end{array}$} & Sex & 1 & 4.93 & 0.64 & 0.026 \\
\hline & $\begin{array}{l}\text { Genetic } \\
\text { Background }\end{array}$ & 9 & 17.6 & 2.27 & 0.04 \\
\hline & Viral Load & 1 & 0.03 & 0.004 & 0.85 \\
\hline & $\mathrm{DPI}$ & 2 & 25.1 & 3.25 & $<0.0001$ \\
\hline & $\begin{array}{l}\text { Sex }{ }^{\star} \text { Genetic } \\
\text { Background }\end{array}$ & 9 & 23.8 & 3.07 & 0.005 \\
\hline & Mating & 1 & 1.33 & 0.18 & 0.25 \\
\hline & $\begin{array}{l}\text { Genetic } \\
\text { Background }\end{array}$ & 8 & 19.0 & 2.53 & 0.025 \\
\hline & Viral Load & 1 & 1.10 & 0.15 & 0.29 \\
\hline & DPI & 2 & 7.66 & 1.02 & 0.022 \\
\hline & $\begin{array}{l}\text { Mating*Genetic } \\
\text { Background }\end{array}$ & 8 & 8.12 & 1.08 & 0.42 \\
\hline
\end{tabular}

849

850 Table 5. Model outputs for the GLM analysis conducted on qualitative DCV shedding

851 (the proportion of sheddings with non-zero readings of DCV). The DPI acronym is

852 used in place of 'days post-infection'. Separate analyses were used to test the effect

853 of sex and mating in females. 


\begin{tabular}{|c|c|c|c|c|c|}
\hline $\begin{array}{l}\text { Response } \\
\text { Variable }\end{array}$ & Predictor & Df & $F$ & $\begin{array}{l}\text { \% Variance } \\
\text { Explained }\end{array}$ & p-value \\
\hline \multirow{10}{*}{$\begin{array}{c}\text { Quantitative } \\
\text { DCV } \\
\text { Shedding }\end{array}$} & Sex & 1 & 0.67 & 0.28 & 0.42 \\
\hline & $\begin{array}{l}\text { Genetic } \\
\text { Background }\end{array}$ & 9 & 2.52 & 9.48 & 0.009 \\
\hline & Viral Load & 1 & 5.03 & 4.21 & 0.007 \\
\hline & DPI & 2 & 0.23 & 0.095 & 0.63 \\
\hline & $\begin{array}{l}\text { Sex*Genetic } \\
\text { Background }\end{array}$ & 9 & 1.73 & 6.53 & 0.082 \\
\hline & Mating & 1 & 0.22 & 0.098 & 0.64 \\
\hline & $\begin{array}{l}\text { Genetic } \\
\text { Background }\end{array}$ & 8 & 1.44 & 5.82 & 0.17 \\
\hline & Viral Load & 1 & 11.2 & 10.1 & $<0.0001$ \\
\hline & DPI & 2 & 0.18 & 0.08 & 0.67 \\
\hline & $\begin{array}{l}\text { Mating }{ }^{\star} \text { Genetic } \\
\text { Background }\end{array}$ & 8 & 2.46 & 8.87 & 0.014 \\
\hline
\end{tabular}

856 Table 6. Model outputs for the GLM analysis conducted on quantitative DCV

857 shedding (the subset of shedding with non-zero readings of DCV). The DPI acronym

858 is used in place of 'days post-infection'. Separate analyses were used to test the

859 effect of sex and mating in females.

860 
861

\begin{tabular}{clcccc}
\hline $\begin{array}{c}\text { Response } \\
\text { Variable }\end{array}$ & Predictor & Df & $x^{2}$ & $\begin{array}{c}\text { \% Deviance } \\
\text { Explained }\end{array}$ & p-value \\
\hline & Sex & 1 & 4.58 & 0.28 & 0.032 \\
$\begin{array}{c}\text { Qualitative } \\
V\end{array}$ & Line & 9 & 38.2 & 2.30 & $<0.0001$ \\
& Sex*Line & 9 & 47.0 & 2.83 & $<0.0001$ \\
\hline
\end{tabular}

862 Table 7. Model outputs for the logistic regression analysis conducted on qualitative

$863 V$ (the proportion of non-zero $V$ values).

864

\begin{tabular}{clcccc}
\hline $\begin{array}{c}\text { Response } \\
\text { Variable }\end{array}$ & Predictor & Df & $F$ & $\begin{array}{c}\text { \% Variance } \\
\text { Explained }\end{array}$ & p-value \\
\hline & Sex & 1 & 0.077 & 0.01 & 0.78 \\
$\begin{array}{c}\text { Quantitative } \\
V\end{array}$ & Line & 9 & 2.51 & 4.13 & 0.008 \\
& Sex*Line & 9 & 6.94 & 11.4 & $<0.0001$ \\
\hline
\end{tabular}

865

866 Table 8. Model outputs for the GLM analysis conducted on quantitative $V$ (the

867 subset with non-zero $V$ values). 
869

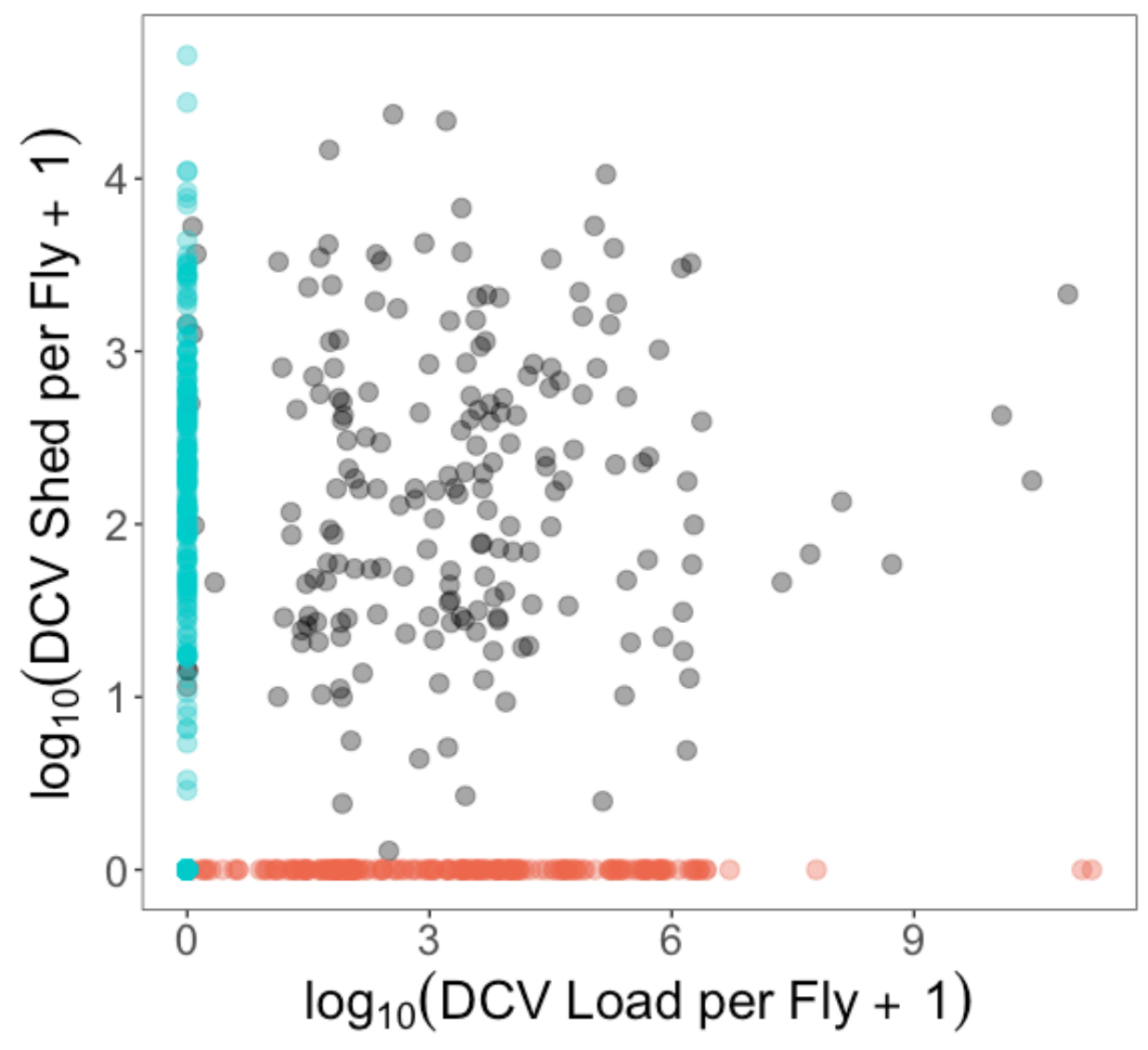

871 Figure S1. The relationship between the viral load of flies and the amount of virus

872 they shed into their environment. The two distinct phenotypes, where individuals

873 show a zero-value for shedding or load and a positive-value for the other trait, are

874 marked by blue (supersponges) or red (supershedders). 


\begin{tabular}{|l|cccccccccc|}
\cline { 2 - 9 } \multicolumn{1}{c|}{} & 59 & 75 & 138 & 373 & 379 & 380 & 502 & 738 & 765 & 818 \\
\hline Male & 20 & 20 & 18 & 19 & 17 & 18 & 17 & 19 & 18 & 19 \\
Female & 17 & 20 & 13 & 19 & 19 & 20 & 19 & 18 & 15 & 18 \\
Virgin Female & 20 & 18 & 7 & 18 & 20 & 19 & 19 & 20 & 16 & 20 \\
\hline
\end{tabular}

877 Table S1 - The number of flies measured for lifespan and viral load at death for

878 each combination of genetic background and sex/female mating status.

879

(a)

\begin{tabular}{|c|cccccccccc|}
\cline { 2 - 10 } \multicolumn{1}{c|}{} & 59 & 75 & 138 & 373 & 379 & 380 & 502 & 738 & 765 & 818 \\
\hline Male & 12 & 11 & 11 & 12 & 11 & 11 & 12 & 11 & 11 & 6 \\
$\begin{array}{c}\text { Mated } \\
\text { Female }\end{array}$ & 13 & 12 & 11 & 12 & 12 & 12 & 11 & 12 & 12 & 12 \\
$\begin{array}{c}\text { Virgin } \\
\text { Female }\end{array}$ & 12 & 14 & NA & 15 & 12 & 13 & 12 & 12 & 7 & 12 \\
\hline
\end{tabular}

(b)

\begin{tabular}{|c|cccccccccc|}
\cline { 2 - 10 } \multicolumn{1}{c|}{} & 59 & 75 & 138 & 373 & 379 & 380 & 502 & 738 & 765 & 818 \\
\hline Male & 12 & 12 & 11 & 12 & 11 & 12 & 11 & 12 & 12 & 6 \\
$\begin{array}{c}\text { Mated } \\
\text { Female }\end{array}$ & 14 & 12 & 11 & 11 & 12 & 11 & 11 & 11 & 12 & 13 \\
$\begin{array}{c}\text { Virgin } \\
\text { Female }\end{array}$ & 12 & 14 & NA & 14 & 12 & 11 & 13 & 10 & 9 & 12 \\
\hline
\end{tabular}

(c)

\begin{tabular}{|c|cccccccccc|}
\cline { 2 - 10 } \multicolumn{1}{c|}{} & 59 & 75 & 138 & 373 & 379 & 380 & 502 & 738 & 765 & 818 \\
\hline Male & 11 & 12 & 12 & 12 & 12 & 11 & 12 & 10 & 12 & 7 \\
$\begin{array}{c}\text { Mated } \\
\text { Female }\end{array}$ & 11 & 11 & 10 & 13 & 12 & 11 & 13 & 11 & 12 & 12 \\
$\begin{array}{c}\text { Virgin } \\
\text { Female }\end{array}$ & 11 & 13 & $N A$ & 13 & 12 & 13 & 11 & 12 & 8 & 11 \\
\hline
\end{tabular}

880

881 Table S2 - The number of viral load samples for each treatment group (a) 1 DPI, (b)

8822 DPI and (c) 3 DPI.

883 
(a)

\begin{tabular}{|c|cccccccccc|}
\cline { 2 - 10 } \multicolumn{1}{c|}{} & 59 & 75 & 138 & 373 & 379 & 380 & 502 & 738 & 765 & 818 \\
\hline Male & 5 & 9 & 2 & 5 & 4 & 6 & 8 & 6 & 5 & 3 \\
$\begin{array}{c}\text { Mated } \\
\text { Female }\end{array}$ & 6 & 5 & 5 & 10 & 8 & 9 & 2 & 9 & 3 & 9 \\
$\begin{array}{c}\text { Virgin } \\
\text { Female }\end{array}$ & 4 & 11 & NA & 11 & 7 & 9 & 4 & 3 & 6 & 4 \\
\hline
\end{tabular}

(b)

\begin{tabular}{|c|cccccccccc|}
\cline { 2 - 10 } \multicolumn{1}{c|}{} & 59 & 75 & 138 & 373 & 379 & 380 & 502 & 738 & 765 & 818 \\
\hline Male & 1 & 5 & 3 & 1 & 1 & 3 & 7 & 6 & 1 & 4 \\
$\begin{array}{c}\text { Mated } \\
\text { Female }\end{array}$ & 8 & 4 & 5 & 5 & 2 & 1 & 1 & 3 & 4 & 1 \\
$\begin{array}{c}\text { Virgin } \\
\text { Female }\end{array}$ & 1 & 3 & NA & 9 & 7 & 7 & 6 & 1 & 5 & 4 \\
\hline
\end{tabular}

(c)

\begin{tabular}{|c|cccccccccc|}
\cline { 2 - 10 } \multicolumn{1}{c|}{} & 59 & 75 & 138 & 373 & 379 & 380 & 502 & 738 & 765 & 818 \\
\hline Male & 1 & 5 & 5 & 5 & 7 & 7 & 1 & 4 & 7 & 6 \\
$\begin{array}{c}\text { Mated } \\
\text { Female } \\
\begin{array}{c}\text { Virgin } \\
\text { Female }\end{array}\end{array}$ & 5 & 4 & 7 & 4 & 5 & 4 & 1 & 7 & 9 & 2 \\
\hline
\end{tabular}

885 Table S3 - The number of non-zero viral load samples for each treatment group (a)

8861 DPI, (b) 2 DPI and (c) 3 DPI.

887

(a)

\begin{tabular}{|c|cccccccccc|}
\cline { 2 - 10 } \multicolumn{1}{c|}{} & 59 & 75 & 138 & 373 & 379 & 380 & 502 & 738 & 765 & 818 \\
\hline Male & 10 & 11 & 10 & 12 & 11 & 10 & 12 & 10 & 10 & 5 \\
$\begin{array}{c}\text { Mated } \\
\text { Female }\end{array}$ & 13 & 12 & 11 & 11 & 12 & 12 & 11 & 12 & 12 & 12 \\
$\begin{array}{c}\text { Virgin } \\
\text { Female }\end{array}$ & 11 & 14 & NA & 15 & 12 & 13 & 12 & 12 & 7 & 12 \\
\hline
\end{tabular}

(b)

\begin{tabular}{|c|cccccccccc|}
\cline { 2 - 10 } \multicolumn{1}{c|}{} & 59 & 75 & 138 & 373 & 379 & 380 & 502 & 738 & 765 & 818 \\
\hline Male & 12 & 12 & 11 & 11 & 10 & 12 & 11 & 12 & 12 & 7 \\
$\begin{array}{c}\text { Mated } \\
\text { Female } \\
\begin{array}{c}\text { Virgin } \\
\text { Female }\end{array}\end{array}$ & 14 & 12 & 11 & 11 & 12 & 11 & 11 & 9 & 12 & 13 \\
\hline
\end{tabular}

(c)

\begin{tabular}{|c|cccccccccc|}
\cline { 2 - 10 } \multicolumn{1}{c|}{} & 59 & 75 & 138 & 373 & 379 & 380 & 502 & 738 & 765 & 818 \\
\hline Male & 10 & 11 & 12 & 12 & 11 & 11 & 12 & 10 & 9 & 7 \\
$\begin{array}{c}\text { Mated } \\
\text { Female } \\
\begin{array}{c}\text { Virgin } \\
\text { Female }\end{array}\end{array}$ & 11 & 9 & 10 & 13 & 9 & 9 & 13 & 8 & 12 & 11 \\
\hline
\end{tabular}

889 Table S4 - The number of virus shedding samples for each treatment group (a) 1

890 DPI, (b) 2 DPI and (c) 3 DPI. 
(a)

\begin{tabular}{|c|cccccccccc|}
\cline { 2 - 10 } \multicolumn{1}{c|}{} & 59 & 75 & 138 & 373 & 379 & 380 & 502 & 738 & 765 & 818 \\
\hline Male & 0 & 7 & 4 & 6 & 3 & 7 & 4 & 6 & 2 & 4 \\
$\begin{array}{c}\text { Mated } \\
\text { Female }\end{array}$ & 5 & 4 & 3 & 6 & 6 & 5 & 1 & 6 & 7 & 4 \\
$\begin{array}{c}\text { Virgin } \\
\text { Female }\end{array}$ & 4 & 6 & NA & 8 & 6 & 4 & 6 & 3 & 5 & 5 \\
\hline
\end{tabular}

(b)

\begin{tabular}{|c|cccccccccc|}
\cline { 2 - 10 } \multicolumn{1}{c|}{} & 59 & 75 & 138 & 373 & 379 & 380 & 502 & 738 & 765 & 818 \\
\hline $\begin{array}{c}\text { Male } \\
\text { Mated }\end{array}$ & 10 & 7 & 6 & 5 & 9 & 9 & 5 & 11 & 7 & 7 \\
$\begin{array}{c}\text { Female } \\
\begin{array}{c}\text { Virgin } \\
\text { Female }\end{array}\end{array}$ & 5 & 4 & 9 & 7 & 8 & 3 & 6 & 3 & 4 & 4 \\
\hline
\end{tabular}

(c)

\begin{tabular}{|c|cccccccccc|}
\cline { 2 - 9 } \multicolumn{1}{c|}{} & 59 & 75 & 138 & 373 & 379 & 380 & 502 & 738 & 765 & 818 \\
\hline $\begin{array}{c}\text { Male } \\
\begin{array}{c}\text { Mated } \\
\text { Female }\end{array}\end{array}$ & 7 & 4 & 8 & 3 & 9 & 2 & 7 & 2 & 3 & 6 \\
$\begin{array}{c}\text { Virgin } \\
\text { Female }\end{array}$ & 4 & 4 & 6 & 7 & 2 & 2 & 3 & 3 & 4 & 5 \\
\hline
\end{tabular}

892 Table S5 - The number of non-zero virus shedding samples for each treatment

893 group (a) 1 DPI, (b) 2 DPI and (c) 3 DPI.

894

895 


\begin{tabular}{|c|c|c|}
\hline $\begin{array}{l}\text { Response } \\
\text { Variable }\end{array}$ & Analysis & Predictors \\
\hline Lifespan & GLM & $\begin{array}{l}\text { Sex * Genetic Background * VLAD } \\
\text { Mating * Genetic Background * VLAD }\end{array}$ \\
\hline VLAD & GLM & $\begin{array}{l}\text { Sex * Genetic Background } \\
\text { Mating * Genetic Background }\end{array}$ \\
\hline $\begin{array}{l}\text { Qualitative } \\
\text { Load }\end{array}$ & $\begin{array}{l}\text { Logistic } \\
\text { Regression }\end{array}$ & $\begin{array}{l}\text { Sex * Genetic Background + DPI } \\
\text { Mating * Genetic Background + DPI }\end{array}$ \\
\hline $\begin{array}{l}\text { Quantitative } \\
\text { Load }\end{array}$ & GLM & $\begin{array}{l}\text { Sex* Genetic Background + DPI } \\
\text { Mating * Genetic Background + DPI }\end{array}$ \\
\hline $\begin{array}{l}\text { Qualitative } \\
\text { Shed }\end{array}$ & $\begin{array}{l}\text { Logistic } \\
\text { Regression }\end{array}$ & $\begin{array}{l}\text { Sex * Genetic Background + Quant. Load + DPI } \\
\text { Mating * Genetic Background + Quant. Load + } \\
\text { DPI }\end{array}$ \\
\hline $\begin{array}{l}\text { Quantitative } \\
\text { Shed }\end{array}$ & GLM & $\begin{array}{l}\text { Sex * Genetic Background + Quant. Load + DPI } \\
\text { Mating * Genetic Background + Quant. Load + } \\
\text { DPI }\end{array}$ \\
\hline Qualitative $V$ & $\begin{array}{l}\text { Logistic } \\
\text { Regression }\end{array}$ & Sex * Genetic Background \\
\hline Quantitative $V$ & GLM & Sex * Genetic Background \\
\hline
\end{tabular}

897 Table S6. Summaries of the logistic regression and GLMs used to analyse the 898 response variables of our experiments. All interactions are fully-factorial and marked 899 using an asterisk $\left(^{\star}\right)$. 